\title{
CPT calibration and analysis for a carbonate sand
}

\author{
D. GIRETTI* , K. BEEN†, V. FIORAVANTE $\ddagger$ and S. DICKENSON§
}

\begin{abstract}
This paper describes a project-based cone penetration test (CPT) calibration on a carbonate sand fill that was hydraulically placed and subsequently densified by vibrocompaction. The project involved the development of an artificial island constructed offshore from the United Arab Emirates for oil and gas production. Carbonate sands have crushable grains and can be significantly more compressible than silica sands, so it was determined that the semi-empirical CPT-based correlations for silica sands were not applicable and a soil-specific calibration was needed for post-densification characterisation of density, shear strength and compressibility. The CPT calibration investigation was primarily undertaken in a centrifuge, and then checked with supplementary tests in a large calibration chamber. In this paper, analysis of the calibration data follows three different threads for comparison with more typical siliceous sands: (a) relationships between CPT tip resistance, void ratio and vertical effective stress; $(b)$ a relationship between CPT tip resistance and state parameter; and $(c)$ an approach based on cavity expansion theory, which provides predictive capability for the CPT once soil properties have been measured in the laboratory. The test results are compared with silica sands, in terms of void ratio or the state parameter $\psi$.
\end{abstract}

KEYWORDS: calcareous soils; centrifuge modelling; in situ testing; sands

\section{INTRODUCTION}

The use of the large-scale, calibration chamber for cone penetration test (CPT) interpretation in sands is considered a robust and advantageous method for developing correlations for the engineering properties of sands (Chapman, 1974; Bellotti et al., 1982; Been et al., 1986). Specimens of the sand are prepared at a known density in a large (greater than about $0.7 \mathrm{~m}$ ) chamber and then consolidated to controlled vertical and horizontal stress conditions. Each test yields a data point of known CPT tip resistance, soil stress conditions (horizontal and vertical geostatic stress) and void ratio of the sand. About ten such tests are needed to develop a correlation between tip resistance and the sand state variables (stress conditions and void ratio). Most published testing was carried out in the 1970s and 1980s as part of research projects to develop something approaching universal correlations for use of CPT interpretation in engineering practice (e.g. Parkin et al., 1980; Baldi et al., 1982, 1986; Lunne \& Christoffersen, 1983; Been et al., 1986, 1987; Mayne, 2007). From a practical perspective, such testing programmes require significant resources, therefore laboratory-based development of soilspecific characterisation is rarely proposed on routine engineering projects, leading to the continued utilisation of semi-empirical correlations, which have been shown to be potentially deficient on many projects.

Carrying out the CPT calibration in a geotechnical centrifuge can be a more cost-effective alternative (Bolton et al., 1999) because the specimen size is many times smaller and a single test gives a tip resistance profile over a wide range of state variables; however, scaling issues must be addressed.

Manuscript received 30 November 2016; revised manuscript accepted 15 June 2017.

Discussion on this paper is welcomed by the editor.

* ISMGEO srl, Seriate, Bergamo, Italy (Orcid:0000-0003-4145-1388).

$\dagger$ Golder Associates Ltd, Halifax, NS, Canada.

\pm University of Ferrara, Ferrara, Italy.

$\S$ New Albion Geotechnical Inc., Reno, NV, USA.
The scaling issue reflects the size of the cone used in the centrifuge (i.e. usually much smaller diameter than the standard field cone) relative to the sand particle sizes, and the need to potentially adjust the laboratory results for field conditions using a standard-sized cone.

The focus of this paper is a CPT calibration on an uncemented carbonate sand, with relatively crushable particles and a high compressibility relative to the silica sands that have been extensively researched and used for correlations in engineering practice. Compressibility has long been recognised as an important parameter when relating tip resistance to relative density, as first noted by Robertson \& Campanella (1983) in comparing calibration chamber correlations for Hilton Mines sand (high compressibility due to the angularity of sand), Ticino sand (medium compressibility) and Monterey sand (low compressibility). The definition of compressibility, and the methods used to quantify the degree of compressibility were not addressed by Robertson and Campanella. Carbonate sands have crushable grains and are considered significantly more compressible than silica sand, which has generally resulted in the exclusion of carbonate sands from existing published literature as they are 'non-textbook' soils. Mayne (2006) provides data for a few carbonate sands (Quiou, Dogs Bay, Ewa and Kingfisher) that span, and extend, the range of compressibility, as defined on the basis of silica sands correlations. The Hydraulic fill manual for dredging and reclamation works (van't Hoff \& van der Kolff, 2012) addresses carbonate soils, given their widespread use in land reclamation projects. Current engineering practice commonly relies on the application of the so-called 'shell correction factor' (SCF, Lunne, 2006) to the correlations developed for silica sands when interpreting CPT data in carbonate sands. The SCF appears to be more a 'shell correction function' as it depends on several variables: $(a)$ type and mineralogy of the sand; (b) relative density (Vesic, 1965; Bellotti \& Jamiolkowski, 1991; Almeida et al., 1991; van't Hoff \& van der Kolff, 2012); and $(c)$ effective stress level, as the tip resistance is a non-linear function of depth. For important projects, however, sitespecific calibrations are recommended for the sake of developing representative engineering characterisation. 
This paper describes a CPT calibration and in-depth geomechanical investigation of a carbonate sand. The field application involves a carbonate sand that was dredged offshore, hydraulically placed and densified by vibrocompaction; thus the soil was recently placed and the effects of time-dependent phenomena such as ageing, cementation and creep should be negligible. The CPT calibration was undertaken mainly in a centrifuge, and then confirmed with a small number of large calibration chamber tests. The results are compared with other silica and carbonate sands. In the process, the authors have tried to avoid using relative density as a comparative state variable owing to the difficulty of consistently measuring the maximum and minimum densities of crushable, carbonate sands. Comparisons are made in terms of void ratio or the state parameter $\psi$ (Been \& Jefferies, 1985). Klotz \& Coop (2001) used a similar approach to interpret centrifuge tests on model driven piles in Dogs Bay (carbonate) and Leighton Buzzard (silica) sands, but they adopted a ratio of stresses as state parameter to quantify the state of the sands. In this study, attempts were made to use different approaches to define the state for the cone resistance in the tested carbonate sand; for the centrifuge CPTs here presented, the state parameter in terms of volume provides a good interpretation of the penetration resistance.

This is a companion paper to one focused on laboratory characterisation of the properties of the same carbonate sand (Giretti et al., 2017). A premise behind these papers is that undisturbed sampling and testing of sand fill materials is impractical. It is time consuming, expensive and not without significant technical issues; therefore, this investigation focused on an integrated programme of laboratory tests to determine the in situ state of the material, from which reliable correlations of engineering properties could be developed using CPT data.

The objective is to provide a comprehensive data set for a carbonate/crushable sand. Analysis of the calibration data follows three different threads for comparison with more typical siliceous sands

(a) relationships between CPT tip resistance, void ratio and vertical effective stress, comparable to correlations published by Jamiolkowski and his co-workers as well as several other authors worldwide (e.g. Jamiolkowski et al., 2003).

(b) relationship between CPT tip resistance and state parameter, within a critical state framework, following the approach of Been and co-workers (e.g. Been et al., 1986, 1987).

(c) a more rigorous approach based on cavity expansion theory, following Shuttle \& Jefferies (1998), which provides predictive capability for the CPT once soil properties have been measured in the laboratory.

\section{CPT CALIBRATION EQUIPMENT \\ AND PROCEDURES \\ The ISMGEO centrifuge}

The ISMGEO (Istituto Sperimentale Modelli Geotecnici, near Bergamo, Italy) geotechnical centrifuge, is a beam centrifuge made up of a symmetrical rotating arm with a diameter of $6 \mathrm{~m}$, a height of $2 \mathrm{~m}$ and a width of $1 \mathrm{~m}$, which gives it a nominal radius of $2 \mathrm{~m}$. The soil sample for centrifuge CPT testing is housed in a $400 \mathrm{~mm}$ dia. cylindrical strongbox with heavy steel wall to avoid lateral strains. Further details can be found in Baldi et al. (1988), Fioravante \& Giretti (2016) and Airoldi et al. (2016).

\section{Pluviation of soil sample}

The soil models are reconstituted by pluvial deposition in air with constant height of fall from a travelling overhead hopper. Dry pluviation is the most reliable and repeatable technique used to achieve a homogeneous sand sample in the laboratory (Fretti et al., 1995). The target soil density (or void ratio) is obtained by selecting the drop height, the size of the hopper and the speed of the travelling hopper. The void ratio is measured before and after the in-flight consolidation because the acceleration field slightly increases the density reached by pluvial deposition. The void ratio at the end of consolidation is adopted as the test void ratio.

After deposition, if the model has to be tested wet, the sand is filled with water through an upward flow with a small hydraulic gradient to avoid soil disturbance. Tap water is used. The water level is kept constant at the target depth during the centrifuge spinning and monitored by miniature pore water pressure transducers (PPT in Fig. 1) installed into the sample during the pluviation process.

\section{Miniature piezocone penetrometer}

A smaller than standard cone is required for centrifuge testing. The ISMGEO miniaturised electrical piezocone has a diameter $d_{\mathrm{c}}$ of $11.3 \mathrm{~mm}$, an apex angle of $60^{\circ}$ and a friction sleeve of $11.3 \mathrm{~mm}$ dia. and $37 \mathrm{~mm}$ long. One load cell measures the cone tip resistance and another one (located at the back of the sleeve, i.e. a subtraction-type cone) measures the cone resistance plus the shaft friction, up to forces of $9.8 \mathrm{kN}$. A Druck PDCR42 pressure transducer (35 bar capacity, located behind the tip with the porous filter at the $\mathrm{u} 2$ location) is installed in the cone for pore water pressure measurements.

\section{Test set-up in centrifuge}

Figure 1 shows a CPT model test scheme, with a view of the surface settlement transducer (LDT) and the miniaturised piezocone, before the penetration. The ratio of the calibration chamber diameter to the cone diameter is 35 , while the cone distance from the sidewall is approximately 17 cone diameters. These values, according to Bolton et al. (1999), are large enough to minimise lateral boundary effects of the calibration chamber on the results. The ratio of the cone diameter $\left(d_{\mathrm{c}}\right)$ to the mean particle size $\left(D_{50}\right)$ is about 33 for M1 sand and 19 for M3 sand (see next section for sand properties).

Gui \& Bolton (1998), based on centrifuge tests on Leighton Buzzard sand, observe that a ratio $d_{\mathrm{c}} / D_{50}>28$ does not affect the results of cone penetration resistance, while they recognise an extra resistance in the tests where $d_{\mathrm{c}} / D_{50}=16$. This extra resistance is proportional to the area ratio $\left(d_{\mathrm{c}}^{\prime} / d_{\mathrm{c}}\right)^{2}$, where $d_{\mathrm{c}}^{\prime}=d_{\mathrm{c}}+D_{50}=$ effective cone diameter. Accordingly, in the case of M1 the extra resistance can be of the order of $6 \%$, about $11 \%$ for M3. However, Gui and Bolton suggest that the effective diameter $d_{\mathrm{c}}^{\prime}$ reduces as the increased stress level induces crushing; therefore, since M1 and M3 have been recognised as very crushable carbonate sands, the extra resistance was considered negligible, as a first approximation.

\section{In-flight $C P T$}

The reconstituted samples in the strongbox are fixed to the swinging basket in the centrifuge and the centrifuge is activated until the target acceleration is reached. The acceleration is held constant for a few minutes and then reduced. This loading and unloading is repeated twice to minimise the effect of boundary skin friction on the sidewall. During 


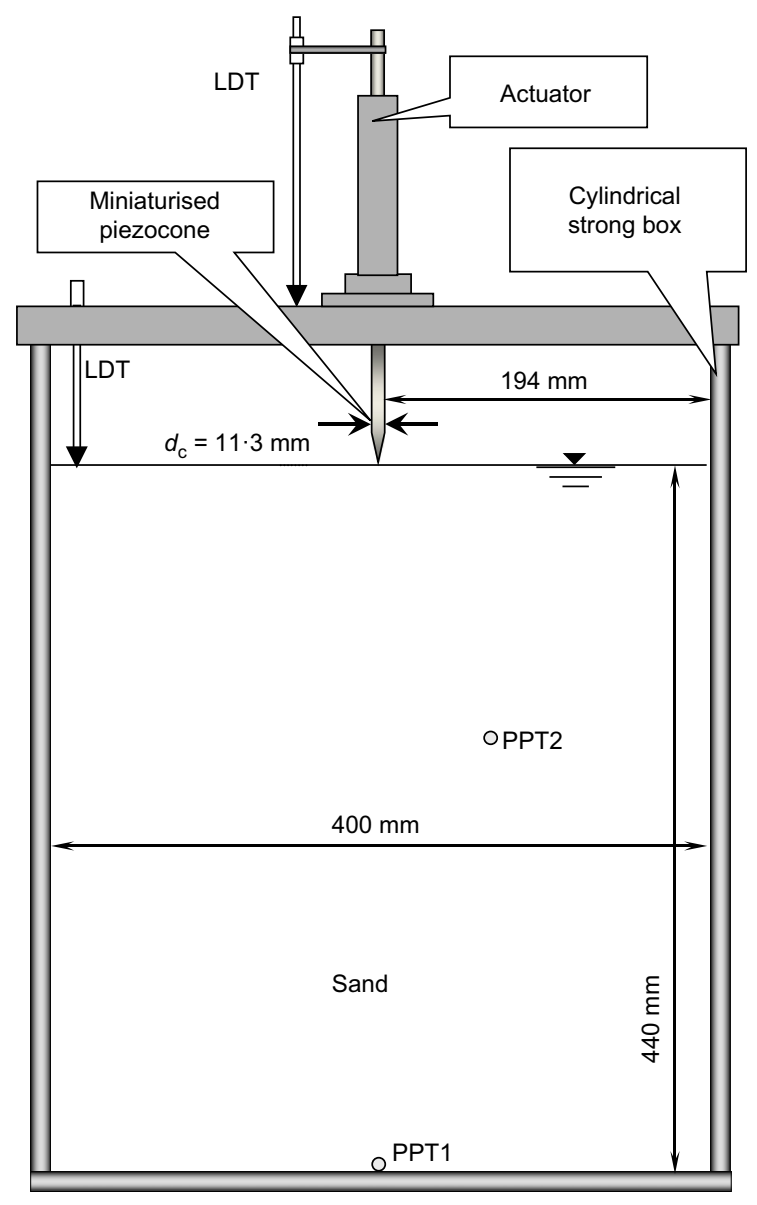

Fig. 1. Test set-up for CPT in the centrifuge strongbox

loading and unloading the settlement of the soil is measured by a potentiometer (LDT on Fig. 1). Finally, the target acceleration is reached again and held constant for the test. When the settlement rate at the top surface becomes negligible and, in saturated samples, the pore pressure transducers measure constant pore pressure values (indicating end of in-flight consolidation) the penetration test is performed at a penetration rate of $0.4 \mathrm{~mm} / \mathrm{s}$. The test penetration is terminated at about 20 cone diameters' distance from the container bottom to avoid rigid boundary effects (Bolton et al., 1999). One test is performed in the central axis of each specimen accelerated at one target value.

Measurements of tip, sleeve friction and pore pressure as a function of penetration are made in the same manner as field CPT. Through the depth of the sample, values are obtained at a range of vertical effective stresses (rather than a single value in a large calibration chamber) because of the high gravity within the centrifuge, in this case $50 \boldsymbol{g}$ and $75 \boldsymbol{g}$ (where $\boldsymbol{g}$ is the earth gravity), for dry and saturated tests, respectively.

\section{The ISMGEO large calibration chamber}

The ISMGEO calibration chamber has been in operation since the 1980s and is described in detail by Bellotti et al. (1982). It houses a $1.42 \mathrm{~m}$ high by $1.2 \mathrm{~m}$ dia. specimen. The equipment consists of a flexible wall chamber, a loading frame, the apparatus for sand deposition and the saturation system.

Two cells enclose the specimen, so that zero average lateral strain boundary conditions can be obtained by keeping the pressure in the outer cell equal to the pressure developed by the specimen in the inner cell. Vertical and horizontal stresses

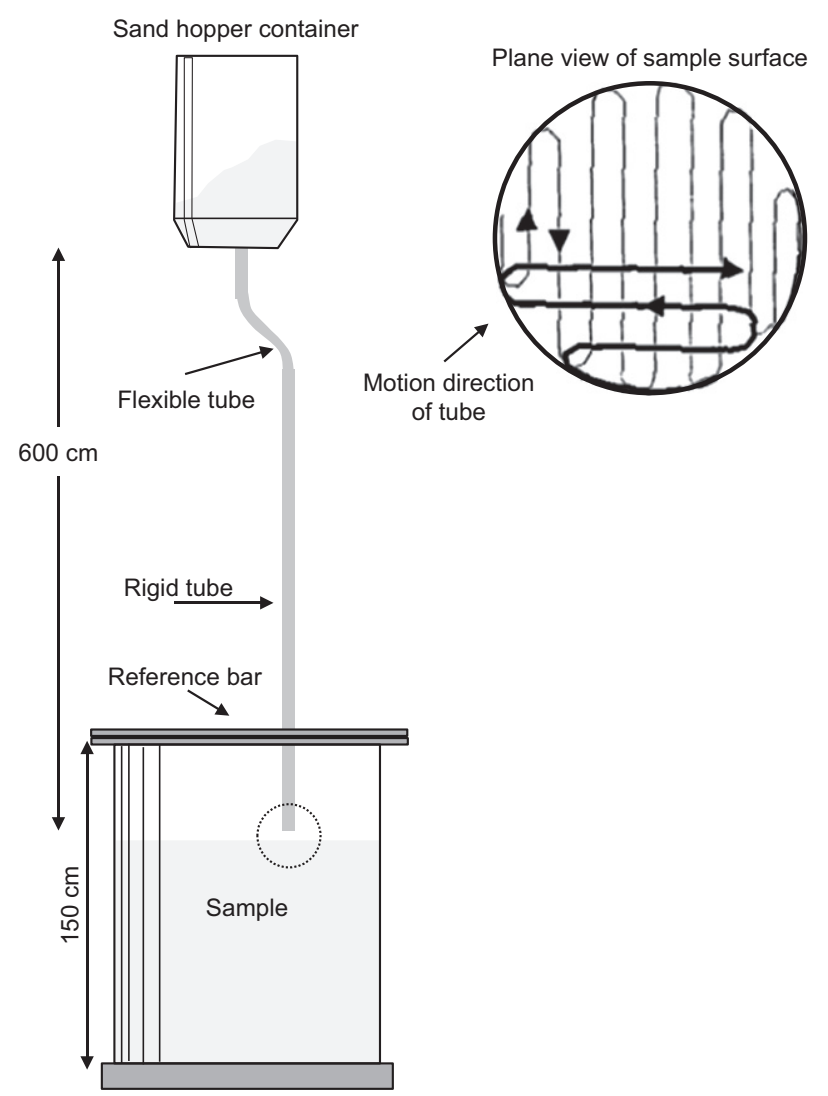

Fig. 2. Large in situ test calibration chamber at ISMGEO

can be independently applied in a controlled manner to the boundaries of the sample. Vertical stresses are applied to the specimen through a piston (positioned at the bottom of the chamber), the horizontal stresses are applied by the pressure of water surrounding the specimen. The cylindrical specimen is enclosed at the sides and base by a membrane; the top of the membrane is sealed around an aluminium plate which confines the specimen at the top and transfers the thrust of the chamber piston from the specimen to a top lid and loading frame to counteract the piston force and to hold the hydro-mechanical press, which pushes the CPT into the chamber.

To control both the stresses and the strains during the saturation and consolidation phase, the following parameters are measured by the data acquisition system: vertical stress, pore pressure within the sample, water pressure in the inner cell (i.e. horizontal stress on the sample), vertical displacement of the chamber piston, horizontal displacements of the specimen (measured by seven linear variable differential transducers (LVDTs) placed at seven different heights of the samples) and specimen volume change.

The CPT probe used in the calibration chamber is a standard piezocone $35.7 \mathrm{~mm}$ in diameter with end area of $10 \mathrm{~cm}^{2}$ and apex angle of $60^{\circ}$. Two load cells measure the tip resistance and the lateral friction independently. A pressure transducer measures the pore water pressure.

\section{Calibration chamber (CC) sample preparation}

The CC specimens are also reconstituted by pluvial deposition in air of the dry sand using a gravity mass sand spreader (Fig. 2). The deposition method is calibrated by changing the drop height and the size of the spreader until the target soil density is obtained. During the sample reconstruction, the membrane is sealed around the top 
edge of the chamber and forced against the specimen former by a low vacuum applied to the inner cell. After sample preparation, the top surface of the specimen is levelled, the top plate is gently lowered and sealed to the membrane. The chamber inner cell is filled with water and the specimen former is removed.

The specimen is saturated through an upwards flow of de-aired water. The water for the specimen saturation, contained in a closed tank of $1 \mathrm{~m}^{3}$ capacity, is de-aired by boiling and vacuum. The pressure inside the specimen is equalised to the atmospheric pressure, then the value of $B$ is checked and, when necessary, back pressure steps are applied to improve saturation. When $B \sim 0.95$, the specimen is consolidated by applying vertical and horizontal stress steps up to the target values.

During the saturation and the consolidation stages, the soil density increases slightly and the void ratio values attained after the consolidation are assumed as the reference values in the test interpretation.

During the tests presented here, the vertical and horizontal stresses at the boundary were constant (i.e. boundary condition $\mathrm{BC} 1$ was used).

\section{PROPERTIES OF THE CARBONATE SAND}

Three batches of the carbonate sand were prepared (M1, M3 and MCC).

The CPT calibration is based mainly on M1 sand, described in detail in a companion paper (Giretti et al., 2017). The sand had been dredged from an offshore borrow area and then placed hydraulically on the island within engineered bunds. M1 sand is a biogenic carbonate sand with a carbonate content higher than $97 \%$. The mineralogy breaks down into mainly aragonite (72-76\%), calcite (10-12\%) and Mg-calcite (11-13\%). In addition to M1, a slightly coarser sand gradation M3 was tested in the centrifuge. For the large calibration chamber a mixed material was required (MCC) as there was insufficient sand from either bulk sample. The particle size distributions for both the M1 and M3 bulk samples are shown on Fig. 3, and also the combined MCC sand.

Specific gravity, maximum and minimum density and void ratio for the materials are summarised in Table 1 .

Undrained and drained triaxial tests were carried out to determine the critical state line (CSL) and stress-dilatancy characteristics of M1 and M3 sands. The resulting critical states are shown in Fig. 4, in both $e-\log p^{\prime}$ (Fig. 4(a)) and $q-p^{\prime}$ space (Fig. 4(b)). In the stress and void ratio range investigated, the critical states in the $e-\log p^{\prime}$ space are almost aligned - that is, they fall in the straight part of the CSL. At lower stress and higher void ratio the CSL should probably curve towards the horizontal (Verdugo \& Ishihara, 1996), but in the stress range of $100-2000 \mathrm{kPa}$ the assumption of a linear CSL was considered acceptable. The equations adopted to define the CSL are the following

$$
e=\Gamma_{1}-\lambda_{10} \log _{10}\left(p^{\prime}\right) \text { in the } e-\log _{10}\left(p^{\prime}\right) \text { space }
$$

and

$$
q=M p^{\prime} \text { in the } q-p^{\prime} \text { space }\left(\mathrm{FL}^{-2}\right)
$$

where $p^{\prime}$ is the mean effective stress; $q$ is deviator stress; $\lambda_{10}$ is the slope of the CSL in $e-\log _{10}\left(p^{\prime}\right) ; \Gamma_{1}$ is the void ratio on the CSL when $p^{\prime}=1 \mathrm{kPa}$; and $M$ is the slope of the CSL in $q-p^{\prime}$ space (or the stress ratio at critical state conditions).

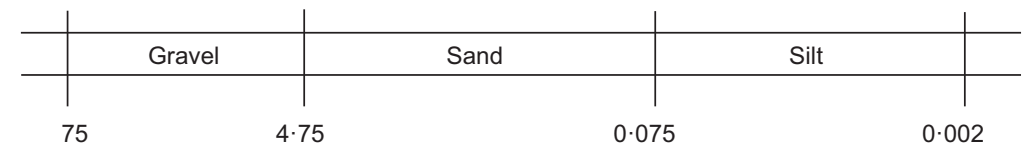

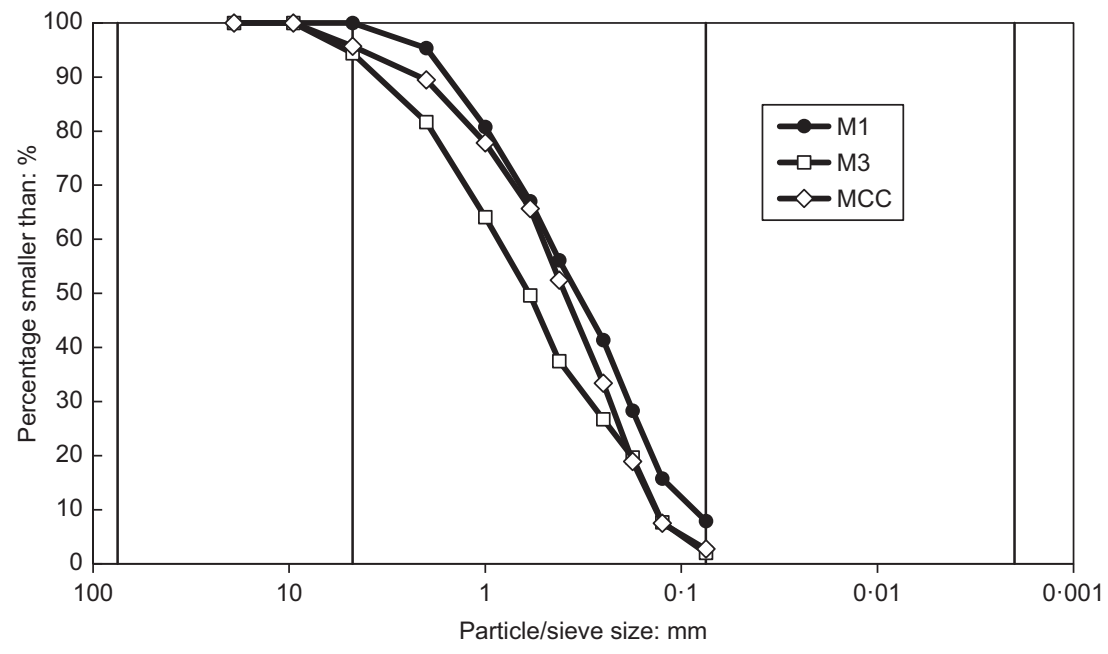

Fig. 3. Grain size distribution of M1, M3 and MCC carbonate sands

Table 1. Index properties of tested sands

\begin{tabular}{l|c|c|c|c|c|c|c|c}
\hline Material & $D_{50}: \mathrm{mm}$ & Fines: $\%$ & Gravel: $\%$ & $\gamma_{\min }{ }^{*}: \mathrm{kN} / \mathrm{m}^{3}$ & $\gamma_{\max } \dagger: \mathrm{kN} / \mathrm{m}^{3}$ & $e_{\max }$ & $e_{\min }$ & $G_{\mathrm{s}}$ \\
\hline M1 & $0 \cdot 34$ & $7 \cdot 9$ & 0 & $14 \cdot 14$ & $17 \cdot 88$ & $0 \cdot 95$ & $0 \cdot 54$ & $2 \cdot 81$ \\
M3 & $0 \cdot 60$ & $2 \cdot 0$ & $5 \cdot 6$ & $13 \cdot 02$ & $16 \cdot 85$ & $1 \cdot 13$ & $0 \cdot 65$ & $2 \cdot 83$ \\
MCC & $0 \cdot 39$ & $2 \cdot 7$ & $4 \cdot 3$ & $13 \cdot 68$ & $17 \cdot 1$ & $1 \cdot 03$ & 0.62 & $2 \cdot 83$ \\
\hline
\end{tabular}

*, $\uparrow$ Measured according to ASTM D4254 (ASTM, 2016a) and ASTM D4253 (ASTM, 2016b), respectively. 


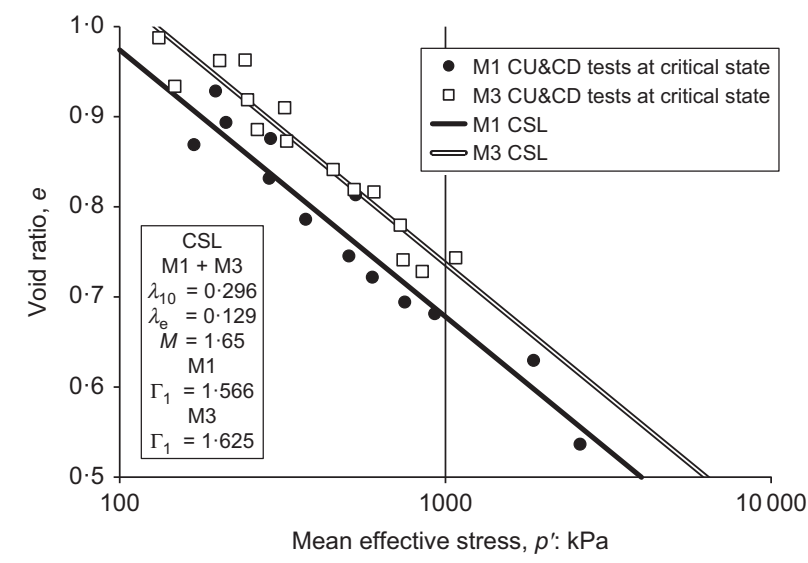

(a)

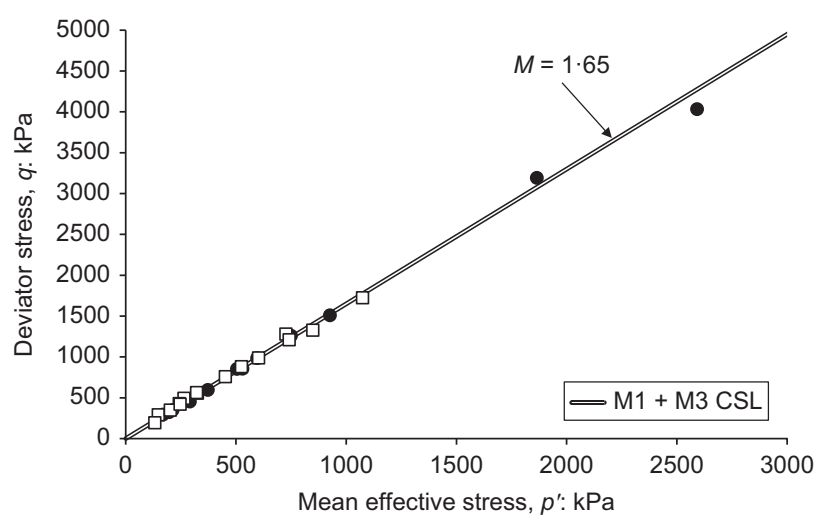

(b)

Fig. 4. Critical state lines for M1 and M3 carbonate sands: (a) $e-\log p^{\prime}$ space; (b) $q-p^{\prime}$ space

Interestingly, Fig. 4(a) shows that the slopes of the CSL for both M1 and M3 are the same, $\lambda_{10}=0 \cdot 296$; however, the ordinate $\left(\Gamma_{1}\right)$ is different. For M1, $\Gamma_{1}=1.566$ and for M3, $\Gamma_{1}=1.625$ consistent with the difference in $e_{\max }$ for the two grain size distributions (Table 1). The critical friction ratio $M=1.65$ (equivalent to a $\phi_{\mathrm{cs}}^{\prime}=40.3^{\circ}$ ) is the same for both M1 and M3.

The slope of the CSL $\lambda_{10}$ is relatively high compared to general trends for silica sands, indicating higher compressibility, while the high stress ratio at the critical state $M$ is attributed to higher intergranular friction for carbonates and interlocking due to the angular particles.

Figure 5 shows the stress dilatancy of the sands, in terms of invariants $\eta_{\max }$ and $D_{\min }$ (defined on Fig. 5). Fig. 6 shows the dilation rate at failure in the drained triaxial tests as a function of the initial (i.e. end of consolidation) state parameter $\psi_{0}$ (the distance in void ratio from the CSL). Figs 5 and 6 confirm that the same stress dilatancy or shearing behaviour for M1 and M3 sands can be used provided $\psi_{0}$ is known (or if the void ratio and stress level are known).

One-dimensional compressibility of the sand materials needs to be known to calculate the void ratio profile and vertical effective stresses in the centrifuge specimens at the test gravity. Large (400 $\mathrm{mm}$ dia.) oedometer tests were carried out both on $\mathrm{M} 1$ and $\mathrm{M} 3$, resulting in a range of $C_{\mathrm{c}}$ values of $0 \cdot 02$ to $0 \cdot 04$.

The horizontal stress ratio $K_{0}$ was measured in zero lateral strain triaxial tests, in which the axial (or deviator) stress is gradually increased, with the confining (horizontal stress) increased accordingly to maintain the zero lateral strain condition, as measured by two proximity transducers with a resolution of 0.2 microns. The results of tests at three void

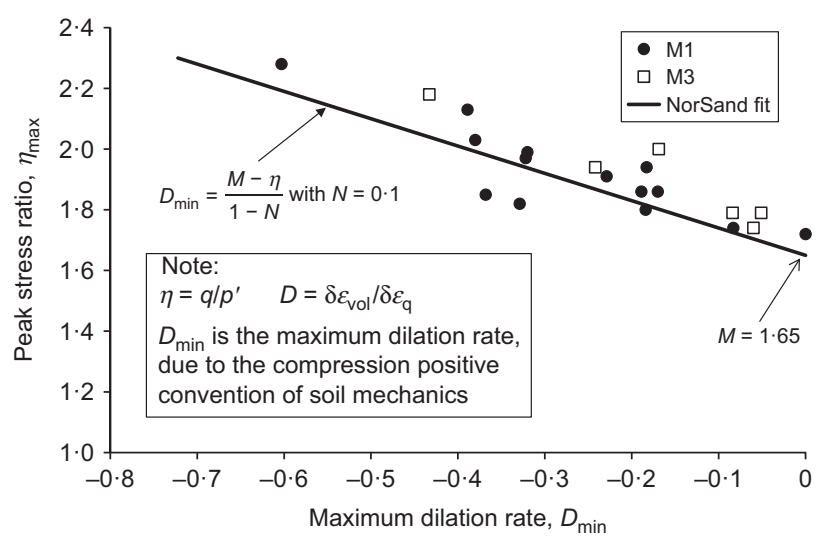

Fig. 5. Stress dilatancy of M1 and M3 sand in terms of invariants $\eta$ and $D$

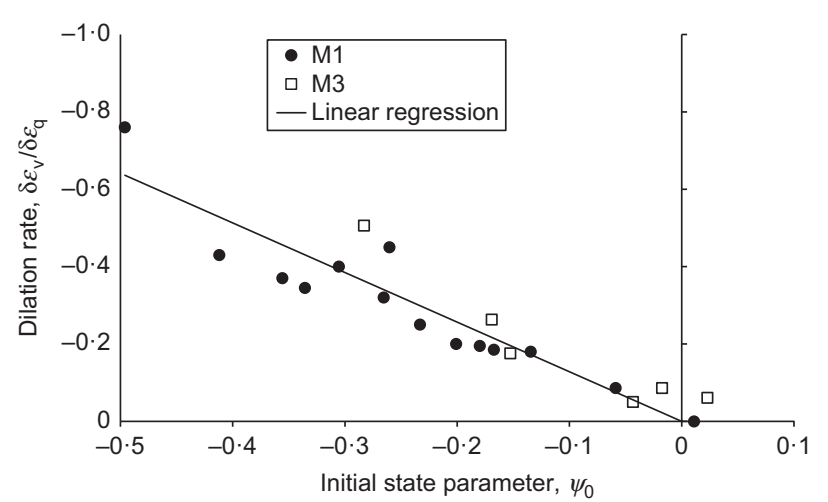

Fig. 6. Dilation rate plotted against initial state parameter for M1 and M3 sands

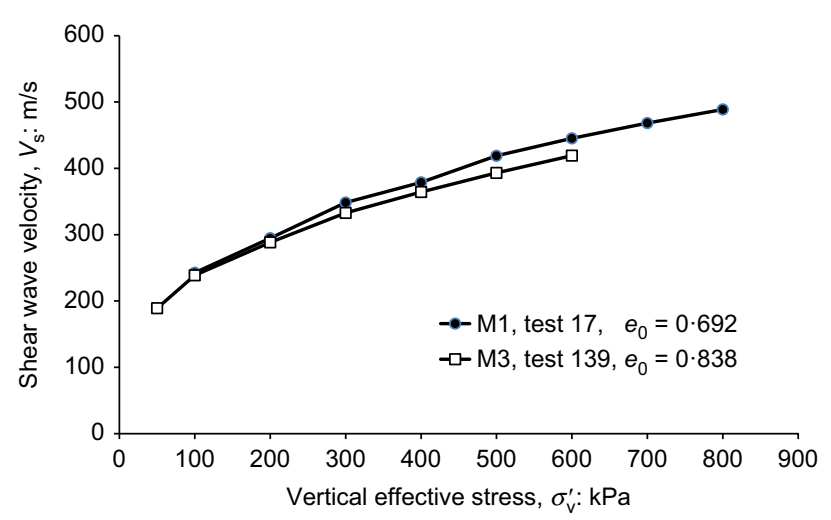

Fig. 7. Shear wave velocity for M1 and M3 sand: results of bender element tests

ratios on M1 sand (Giretti et al., 2017) led to the selection of $K_{0}=0 \cdot 5$ as a reasonable average value for the specimens in the centrifuge strong box.

Finally, CPTu interpretation can benefit from knowledge of the elastic (small-strain) shear modulus - that is, $G_{\max }$. Shear modulus can be calculated from shear wave velocity $V_{\mathrm{s}}$ measured on laboratory samples using bender elements and varies as a function of effective stress, void ratio and granular structure of the soil. Shear wave velocity measurements on two selected laboratory triaxial samples of M1 and M3 sand with bender elements are shown on Fig. 7. The entire data set was used to develop a correlation between $V_{\mathrm{s}}$, the effective 
stresses $\sigma_{\mathrm{v}}^{\prime}$ and $\sigma_{\mathrm{h}}^{\prime}$ and the void ratio $e_{0}$ for both materials.

$$
V_{s}=S_{1} e_{0}^{S_{\mathrm{d}}}\left(\frac{\sigma_{\mathrm{v}}^{\prime}}{p_{\text {ref }}}\right)^{s_{\mathrm{v}}}\left(\frac{\sigma_{\mathrm{h}}^{\prime}}{p_{\text {ref }}}\right)^{s_{\mathrm{h}}}\left(\mathrm{LT}^{-1}\right)
$$

where $S_{1}=215 \mathrm{~m} / \mathrm{s}, s_{\mathrm{d}}=-0.4, s_{\mathrm{v}}=0.187$ and $s_{\mathrm{h}}=0.128$ are calibration coefficients, and $p_{\text {ref }}=100 \mathrm{kPa}$ is the reference atmospheric pressure.

$G_{\max }$ is calculated from the shear wave velocity $V_{\mathrm{s}}$ by

$$
G_{\max }=\rho V_{\mathrm{s}}^{2} \quad\left(\mathrm{FL}^{-2}\right)
$$

where $\rho$ is the mass density of the material.

\section{CLASS B PREDICTION OF CPT CALIBRATION IN TERMS OF STATE PARAMETER $\Psi_{0}$}

During the centrifuge calibration testing, a Class B prediction (Lambe, 1973) of the results was made using critical state theory and the method of calculating the state parameter from the CPT tip resistance provided by Jefferies \& Been (2006, 2015) and Shuttle \& Jefferies (1998).

The CPT data in sands are correlated to the state parameter, $\psi_{0}$, using the equation

$$
Q_{\mathrm{p}}=k \exp \left(-m \psi_{0}\right)
$$

in which $Q_{\mathrm{p}}$ is the normalised tip resistance $\left(q_{\mathrm{t}}-p\right) / p^{\prime}$ and the parameters $k$ and $m$ depend on the soil properties, as indicated in equations (6) and (7). Been et al. $(1986,1987)$ related $k$ and $m$ to the slope of the CSL $\left(\lambda_{10}\right)$ as a proxy for plastic hardening. However, there was still a systematic stress level effect in the correlations, identified by Sladen (1989). Shuttle \& Jefferies (1998), based on numerical modelling using cavity expansion theory and a critical state model called NorSand (Jefferies, 1993), identified that utilisation of low-strain shear modulus, $G_{\max }$, improved the modelling capability of NorSand. Shear modulus and shear resistance scale differently with stress level (shear resistance is linear with stress and $G_{\max }$ scales approximately with square root of stress), which contributed to an apparent stress level bias in the original work. Shuttle and Jefferies identified the following equations as a reasonable approximation to $k$ and $m$ for drained CPT penetration, based on large calibration test data on silica sands

$$
\begin{aligned}
& k=\left[f_{1}\left(G_{\max } / p^{\prime}\right) f_{2}\left(M_{\mathrm{tc}}\right) f_{3}(N) f_{4}(H) f_{5}\left(\lambda_{10}\right) f_{6}(v)\right]^{1.45} \\
& m=1.45 f_{7}\left(G_{\max } / p^{\prime}\right) f_{8}\left(M_{\mathrm{tc}}\right) f_{9}(N) f_{10}(H) f_{11}\left(\lambda_{10}\right) f_{12}(v)
\end{aligned}
$$

where the functions $f_{1}-f_{12}$ are given in Table 2 .

The parameters from the laboratory tests and the NorSand parameters in the above equations were derived for M1 sand and are given in Table 3 . The only parameter in Table 3 that requires further explanation is the plastic hardening modulus, $H$. Plastic modulus depends on the constitutive model and, in this case, the constitutive model is NorSand. There is no straightforward graphical procedure to determine $H$ : it is estimated by modelling the stress-strain behaviour of the triaxial tests using NorSand, as described in Shuttle \& Jefferies (1998). The critical state and stress dilatancy parameters are input in the NorSand model and an axial compression test is simulated. The NorSand simulation is compared to the actual triaxial compression test result, and the parameter $H$ is varied to obtain the best fit to deviator stress and volumetric strain curves. Fig. 8 shows reasonable fits to a dense specimen $(Z 19, H=100)$ and a loose specimen (Z57, $H=40$ ). The influence of $H$ on simulated behaviour is

Table 2. Approximate functions for $k$ and $m$ (Shuttle \& Jefferies, 1998)

\begin{tabular}{l|l|l}
\hline Function & Soil behaviour & Approximation \\
\hline$f_{1}: G_{\max } / p^{\prime}$ & Small-strain shear stiffness & $3 \cdot 79+1 \cdot 12 \ln \left(G_{\max } / p^{\prime}\right)$ \\
$f_{2}: M_{\mathrm{tc}}$ & Critical friction ratio (in triaxial compression) & $1+1 \cdot 06\left(M_{\mathrm{tc}}-1 \cdot 25\right)$ \\
$f_{3}: N$ & Stress dilatancy (Fig. 5) & $1-0 \cdot 30(N-0 \cdot 2)$ \\
$f_{4}: H$ & Plastic hardening modulus & $(H / 100)^{0 \cdot 326}$ \\
$f_{5}: \lambda_{10}$ & Slope of the CSL in $e-\log _{10}\left(p^{\prime}\right)$ & $1-1 \cdot 55\left(\lambda_{10}-0 \cdot 01\right)$ \\
$f_{6}: v$ & Poisson ratio & Unity \\
$f_{7}: G_{\max } / p^{\prime}$ & Small-strain shear stiffness & $1 \cdot 04+0 \cdot 46 \ln \left(G_{\max } / p^{\prime}\right)$ \\
$f_{8}: M_{\mathrm{tc}}$ & Critical friction ratio (in triaxial compression) & $1-0 \cdot 40\left(M_{\mathrm{tc}}-1 \cdot 25\right)$ \\
$f_{9}: N$ & Stress dilatancy (Fig. 5) & $1-0 \cdot 30(N-0 \cdot 2)$ \\
$f_{10}: H$ & Plastic hardening modulus & $(H / 100)^{0 \cdot 15}$ \\
$f_{11}: \lambda_{10}$ & Slope of the CSL in $e-\log _{10}\left(p^{\prime}\right)$ & $1-2 \cdot 21\left(\lambda_{10}-0 \cdot 01\right)$ \\
$f_{12}: v$ & Poisson ratio & Unity \\
\hline
\end{tabular}

Table 3. Material parameters for M1 sand CPT correlation to state parameter

\begin{tabular}{l|l|l}
\hline Parameter & Value & Description \\
\hline$\lambda_{10}$ & $0 \cdot 296$ & Slope of CSL \\
$M_{\mathrm{tc}}$ & $1 \cdot 65$ & Stress ratio at critical state (Fig. 4) \\
$N^{*}$ & $0 \cdot 1$ & Stress dilatancy volumetric coupling parameter (Fig. 5) \\
$H$ & 85 & Plastic hardening modulus (from fitting to triaxial stress-strain curves using NorSand (see Shuttle \& Jefferies, 1998)) \\
$G_{\mathrm{max}}$ & $\rho V_{\mathrm{s}}^{2}$ & Shear wave velocity $V_{\mathrm{s}}$ from equation (3) \\
$v$ & $0 \cdot 25$ & Poisson ratio (estimated) \\
$K_{0}$ & $0 \cdot 5$ & Horizontal stress ratio $\left(\sigma_{\mathrm{h}}^{\prime} / \sigma_{\mathrm{v}}^{\prime}\right)$ \\
$G_{\mathrm{s}}$ & $2 \cdot 82$ & Specific gravity of particles (Table 1) \\
$C_{\mathrm{c}}$ & $0 \cdot 025$ & Coefficient of compressibility, to calculate change in void ratio with stress level in centrifuge chamber \\
$\gamma_{\mathrm{w}}$ & $9 \cdot 81$ & Unit weight of water $\left(\mathrm{kN} / \mathrm{m}^{3}\right)$ \\
\hline
\end{tabular}

*When the Class B prediction was made, $N$ was assumed equal to $0 \cdot 13$. With more data, $N=0 \cdot 1$ is reasonable. The difference in the Class $\mathrm{B}$ prediction is less than $1 \%$. 
illustrated in Fig. 9, which shows the same test curve for Z19, but with $H$ values of 50, 100 and 200. $H=100$ in this case provides the best fit to both the deviator stress and volumetric strain behaviour. It is worth noting that the selection of $H$ may be a function of the strain range of primary interest, with the value of $H$ selected by the analyst to best represent the soil behaviour in a prescribed range of strain. This could have implications for estimation of properties such as secant modulus in iterative analyses requiring soil stiffness at small to moderate strain.

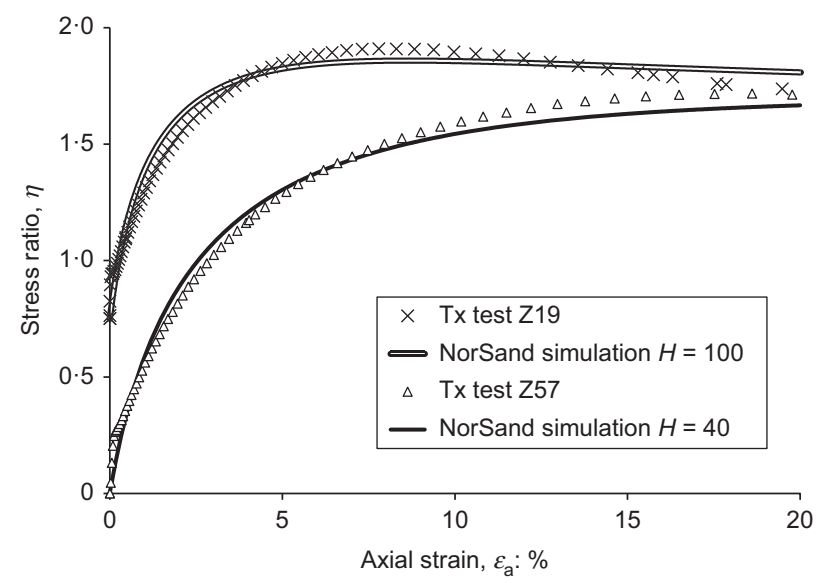

(a)

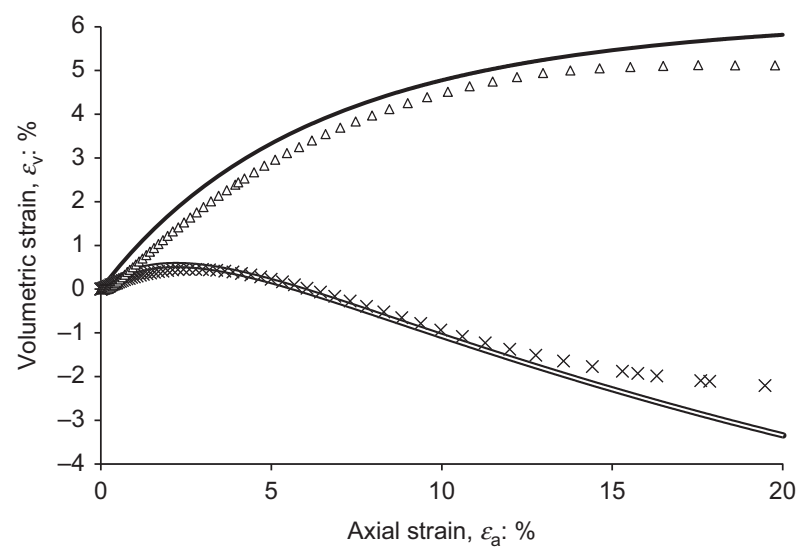

(b)

Fig. 8. NorSand simulations of triaxial tests on M1 sand to estimate hardening parameter $H$ : (a) stress ratio and (b) volumetric strain plotted against axial strain for dense (Z19) and loose (Z57) specimens

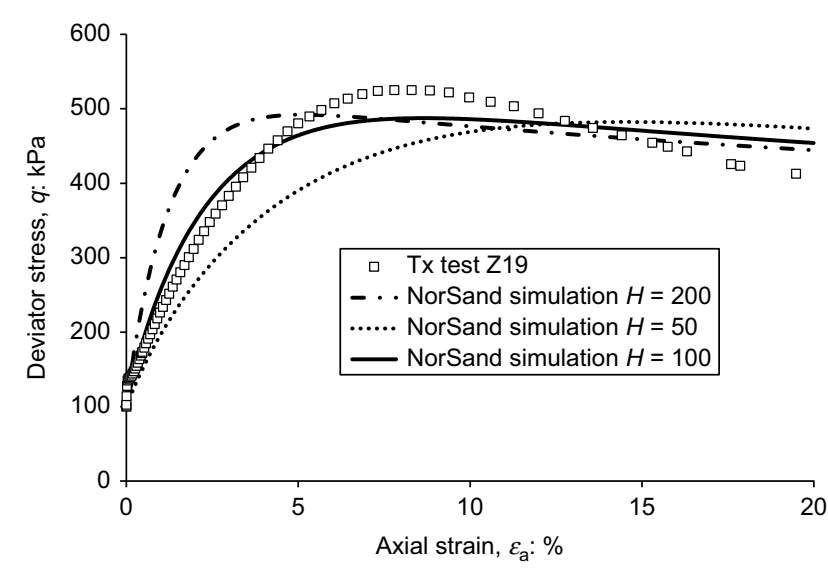

Fig. 9. Effect of varying hardening parameter $H$ on the simulated stress-strain curve for $\mathrm{Z19}$
For M1 sand an average $H=85$ was selected (the range from 13 tests was from 40 to 120 ).

Equations (5)-(7) are used to develop the relationship between CPT tip resistance and vertical stress for a range of average void ratios in the centrifuge calibration tests shown in Fig. 10(a). A primary goal of this investigation was the development of a soil-specific trend in the tip resistancestate parameter; therefore, Fig. 10(b) shows the same information presented as $Q_{\mathrm{p}}$ plotted against $\psi_{0}$, in accordance with equation (5). The Class B predicted values are $k=35$, $m=5 \cdot 1$. These values are significantly out of the range for silica-rich sand, as addressed in a subsequent section of the paper.

\section{CENTRIFUGE CALIBRATION RESULTS}

The results of the CPT calibration tests, comprising 18 tests in the centrifuge and four tests in a large calibration chamber, are summarised in Table 4 . The dry and saturated unit weight and void ratio values are average values and refer to the end of consolidation (in-flight consolidation in the case of centrifuge tests). Both dry and saturated tests were carried out on M1 sand, but only saturated tests on M3.

Figure 11 shows five typical centrifuge calibration test results of saturated M1 sand over a range of average void ratios. The tip resistance is plotted against the vertical effective stress, computed accounting for the acceleration field distortion in the centrifuge. In order to take into account the progressive mobilisation of the cone resistance from the
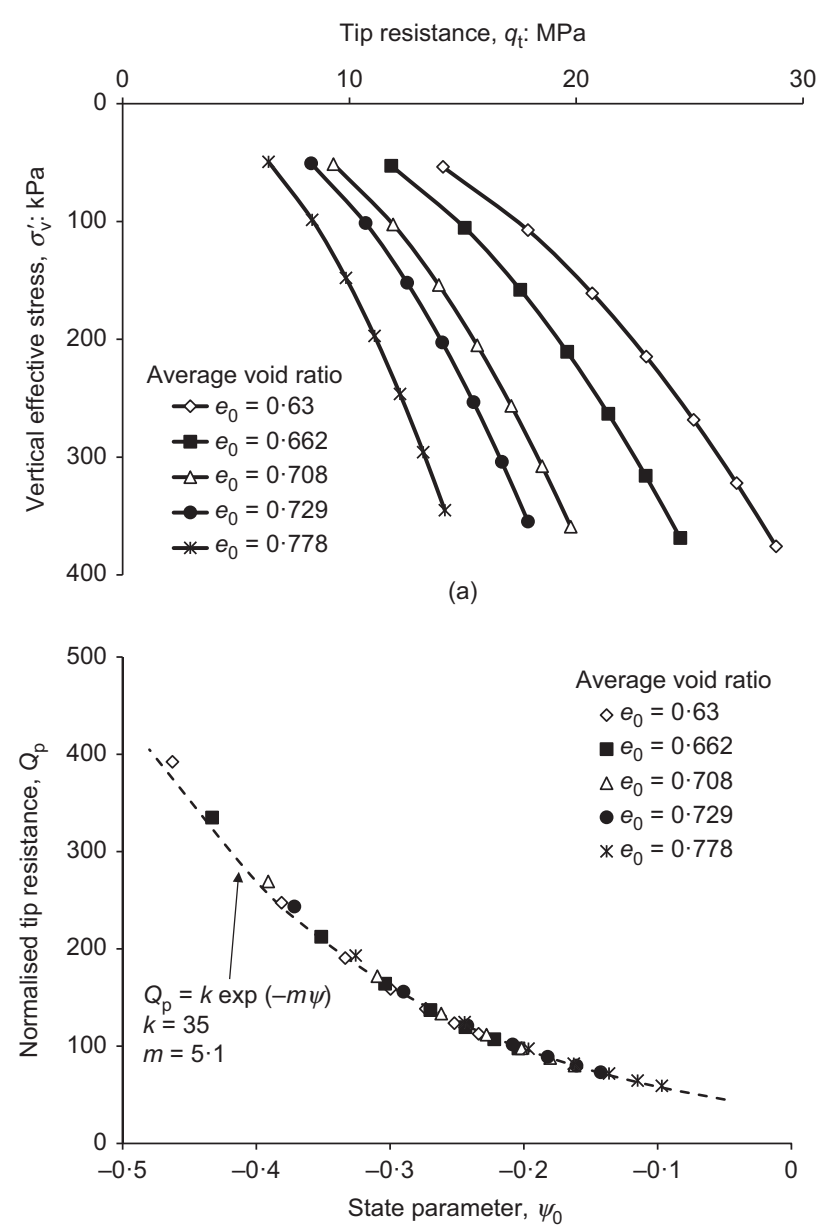

(b)

Fig. 10. Class B prediction of centrifuge tests based on critical state model (Shuttle \& Jefferies, 1998) as detailed in Jefferies \& Been (2015): (a) in terms of void ratio and vertical stress; (b) in terms of state parameter and normalised tip resistance 
Table 4. Centrifuge and large calibration chamber test programme

\begin{tabular}{|c|c|c|c|c|c|}
\hline Test no. & Material & Acceleration: $n g$ & Void ratio, $e_{0}$ & Dry unit weight, $\gamma_{\text {dry }, 0}: \mathrm{kN} / \mathrm{m}^{3}$ & Saturated unit weight, $\gamma_{\text {tot }, 0}: \mathrm{kN} / \mathrm{m}^{3}$ \\
\hline \multicolumn{6}{|c|}{ Centrifuge dry tests } \\
\hline 1 & M1 & 50 & $0 \cdot 823$ & $15 \cdot 13$ & - \\
\hline 2 & M1 & 50 & $0 \cdot 727$ & $15 \cdot 97$ & - \\
\hline 3 & M1 & 50 & $0 \cdot 871$ & $14 \cdot 74$ & - \\
\hline 4 & M1 & 50 & 0.768 & $15 \cdot 6$ & - \\
\hline 5 & M1 & 50 & $0 \cdot 806$ & $15 \cdot 27$ & - \\
\hline 6 & M1 & 50 & $0 \cdot 708$ & $16 \cdot 15$ & - \\
\hline 7 & M1 & 50 & $0 \cdot 666$ & $16 \cdot 56$ & - \\
\hline 8 & M1 & 50 & $0 \cdot 714$ & $16 \cdot 1$ & - \\
\hline \multicolumn{6}{|c|}{ Centrifuge saturated tests } \\
\hline 1 & M1 & 75 & $0 \cdot 707$ & $16 \cdot 16$ & $20 \cdot 02$ \\
\hline 2 & M1 & 75 & 0.662 & $16 \cdot 6$ & $20 \cdot 35$ \\
\hline 3 & M1 & 75 & $0 \cdot 877$ & $14 \cdot 7$ & $19 \cdot 17$ \\
\hline 4 & M1 & 75 & 0.776 & $15 \cdot 53$ & $19 \cdot 44$ \\
\hline 5 & M1 & 75 & $0 \cdot 778$ & $15 \cdot 52$ & $19 \cdot 54$ \\
\hline 6 & M1 & 75 & $0 \cdot 729$ & $15 \cdot 96$ & $20 \cdot 04$ \\
\hline 7 & M1 & 75 & 0.629 & $16 \cdot 94$ & $20 \cdot 6$ \\
\hline 8 & M3 & 75 & $0 \cdot 937$ & $14 \cdot 32$ & $19 \cdot 01$ \\
\hline 9 & M3 & 75 & 0.855 & $14 \cdot 96$ & $19 \cdot 35$ \\
\hline 10 & M3 & 75 & $0 \cdot 765$ & $15 \cdot 72$ & $19 \cdot 86$ \\
\hline \multicolumn{6}{|c|}{ Large calibration chamber saturated tests } \\
\hline 1 & MCC & 1 & $0 \cdot 790$ & $15 \cdot 48$ & $19 \cdot 78$ \\
\hline 2 & MCC & 1 & $0 \cdot 777$ & $15 \cdot 59$ & $19 \cdot 92$ \\
\hline 3 & $\mathrm{MCC}$ & 1 & $0 \cdot 711$ & $16 \cdot 19$ & $20 \cdot 35$ \\
\hline 4 & MCC & 1 & $0 \cdot 703$ & $16 \cdot 27$ & $20 \cdot 45$ \\
\hline
\end{tabular}

model free surface (Schmertmann, 1978; Gui \& Bolton, 1998), the measurements registered in the first six cone diameters of penetration from the surface (or approximately $50 \mathrm{kPa}$ vertical effective stress) were removed, after which the $q_{\mathrm{t}}$ profiles seem not significantly affected by boundary effects. The reported $q_{\mathrm{t}}$ measures are not affected by top and bottom boundary effects.

Two important aspects of the testing are required to interpret the data.

- The average void ratio is shown on Fig. 11 for each specimen. For example, a reported void ratio 0.662 is shown but the initial void ratio was $0 \cdot 675$. The sample consolidated to an average $e_{0}=0.662$ during the centrifuge test as the gravity increased the vertical effective stress. Since the vertical effective stress increases significantly from top to bottom of the sample, the void ratio change due to consolidation also varies through the sample. The void ratio profile in the sample is therefore calculated using the compression coefficients measured in oedometer tests, but maintaining the measured average void ratio.

- The vertical stress conditions with depth are calculated from the void ratio profile and specific gravity of the material. Horizontal stress conditions cannot be measured in the strongbox, so the horizontal stress must be calculated from an assumed stress ratio $K_{0}$. $K_{0}$ is appropriate because the strongbox walls are very stiff and zero lateral strain is a reasonable assumption. Based on triaxial $K_{0}$ consolidation tests, $K_{0}$ has been taken as $0 \cdot 5$.

Similar data are shown for dry M1 sand on Fig. 12 and saturated M3 sand on Fig. 13, with all materials showing the expected increase in tip resistance with reducing void ratio and increasing effective stress. Saturated as opposed to dry conditions have a significant effect on the measured tip resistance for M1 sand. This issue is discussed in a subsequent section of this paper.

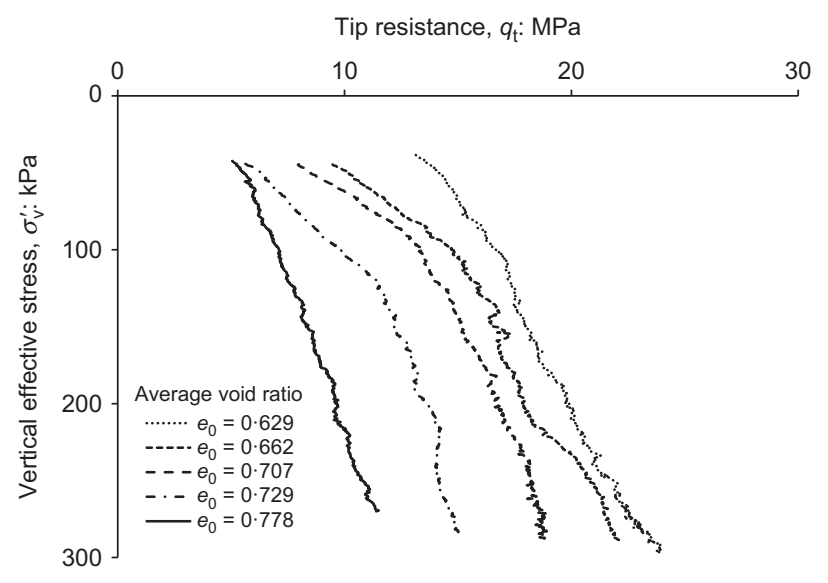

Fig. 11. Selected centrifuge tests at different average void ratio on saturated M1 sand

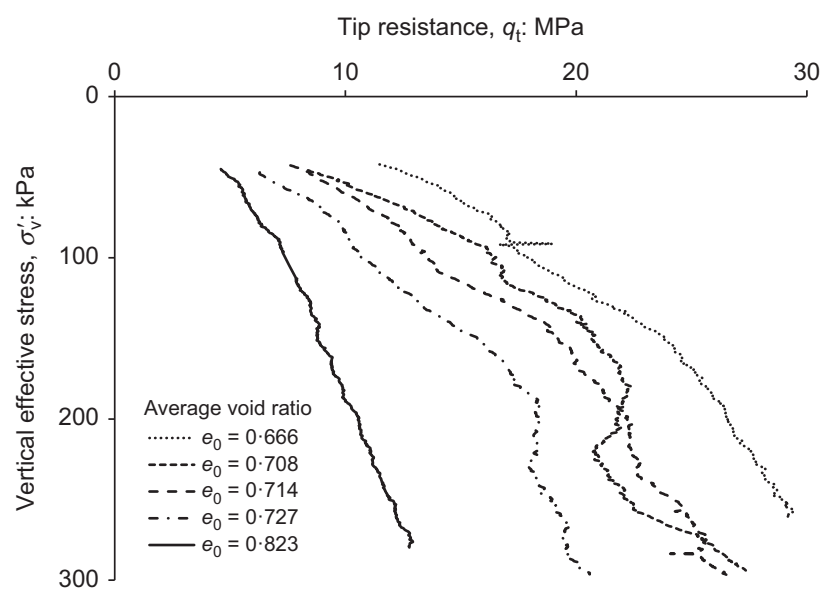

Fig. 12. Selected centrifuge tests at different average void ratio on dry M1 sand 


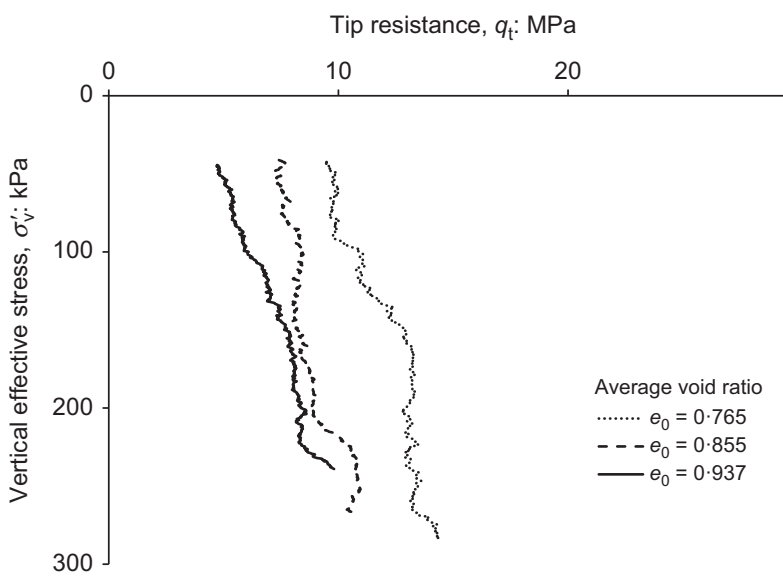

Fig. 13. Selected centrifuge tests at different average void ratio on saturated M3 sand

Table 5. Correlation parameters from centrifuge calibrations for M1 and $\mathrm{M3}$ sand

\begin{tabular}{l|c|c|c}
\hline Parameter & Dry M1 & Saturated M1 & Saturated M3 \\
\hline$F$ & 40.25 & 34.66 & 51.54 \\
$\alpha$ & -3.72 & -3.34 & -2.76 \\
$\beta$ & 0.52 & 0.36 & 0.23 \\
\hline
\end{tabular}

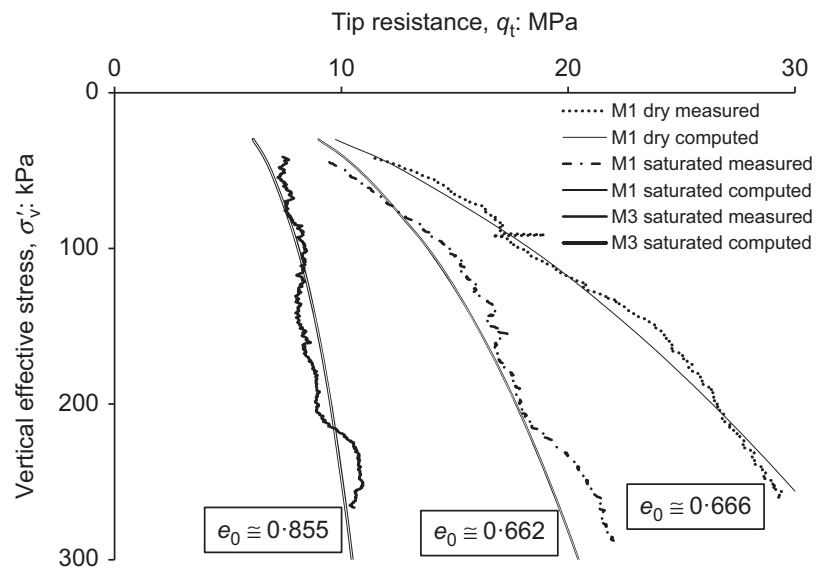

Fig. 14. Fit between measured data in three centrifuge tests and computed curves from equation (8) and parameters in Table 5

\section{Interpretation in terms of void ratio}

The CPT tests performed in a centrifuge have been used to develop correlations between the cone resistance, $q_{\mathrm{t}}$, the void ratio, $e_{0}$, and the vertical effective stress, $\sigma_{\mathrm{v}}^{\prime}$, for M1 and M3 sands. The calibrated correlation has the following equation (Fioravante et al., 1998)

$$
q_{\mathrm{t}}=p_{\text {ref }} F e_{0}^{\alpha}\left(\frac{\sigma_{\mathrm{v}}^{\prime}}{p_{\text {ref }}}\right)^{\beta} \quad\left(\mathrm{FL}^{-2}\right)
$$

with $F, \alpha$ and $\beta$ variable for dry and saturated conditions, and $p_{\text {ref }}$ is $100 \mathrm{kPa}$. The computed calibration coefficients providing best fits to the centrifuge data are given in Table 5 .

Figure 14 shows the comparison between the fitting equation (8) and CPT tip resistance trends from three of the 18 centrifuge tests on M1 and M3 sand.

\section{Verification against large calibration chamber results}

As previously noted, four large calibration chamber tests were carried out on MCC sand to verify the results of the
Table 6. Results of large calibration chamber tests on MCC sand

\begin{tabular}{l|c|c|c|c}
\hline Test number & $e_{0}$ & $\sigma_{\mathrm{v}}^{\prime}: \mathrm{kPa}$ & $\sigma_{\mathrm{h}}^{\prime}: \mathrm{kPa}$ & $q_{\mathrm{t}}: \mathrm{MPa}$ \\
\hline MCC1 & $0 \cdot 790$ & 80 & 40 & $7 \cdot 3$ \\
MCC1 & $0 \cdot 777$ & 200 & 100 & $11 \cdot 6$ \\
MCC2 & $0 \cdot 711$ & 80 & 40 & $11 \cdot 0$ \\
MCC2 & $0 \cdot 703$ & 200 & 100 & $16 \cdot 0$ \\
\hline
\end{tabular}

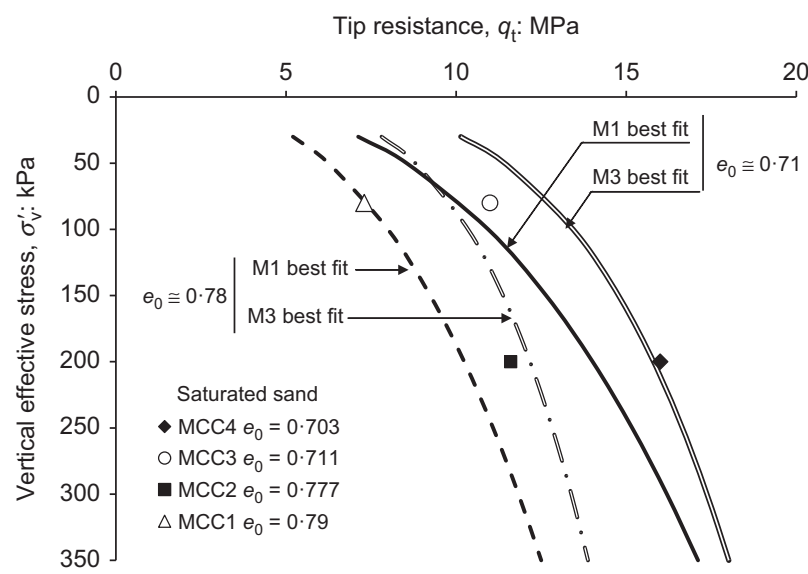

Fig. 15. Validation of centrifuge test with large calibration chamber data, showing that scale effects in centrifuge tests are negligible in this instance

centrifuge CPT calibrations with a miniature cone. Table 6 shows the results of these large calibration chamber tests. They are compared to the centrifuge calibration equations for M1 and M3 sands on Fig. 15. Direct comparison is not possible because the M1, M3 and MCC grain size distributions and index void ratios are slightly different (Fig. 3 and Table 1), and due to inherent experimental scatter in calibration data (both in the centrifuge and large chambers, and in terms of the CPT test). The information can be compared at two void ratios for which there are large calibration chamber tests - that is, $e_{0}=0.78$ and $e_{0}=0.71$, and for which the correlation curves for M1 sand and M3 sand have been calculated using equation (8) and parameters in Table 5. The calibration chamber tests lie in the range of M1 and M3 sands in the centrifuge tests. Fig. 15 is taken as verification that there is not a significant scaling effect in using a miniature cone in the centrifuge and that the centrifuge calibration can be used at face value.

\section{State parameter assessment}

Figure 16 shows the same centrifuge data from Fig. 11, but now processed as a normalised tip resistance $Q_{\mathrm{p}}$ plotted against state parameter $\psi_{0}$. The state parameter is calculated for each point based on the vertical effective stress (as for Fig. 11), horizontal effective stress from $K_{0}=0 \cdot 5$, void ratio estimated at that point and a linear CSL approximation given in equation (1) with $\lambda_{10}=0 \cdot 296$ and $\Gamma_{1}=1 \cdot 566$. The five lines of data are expected to describe a unique relationship given the normalisation and expectation that $\psi_{0}$ is the most significant influence on tip resistance in sands. With minor deviation, especially at low stresses in the test (which is when $\psi_{0}$ is $<-0 \cdot 3$ on Fig. 16), this expectation is realised in Fig. 16.

Figure 16 also shows the line from the Class B prediction based on critical state theory and NorSand, developed with empirical reference back to calibration chamber tests on silica sands. The trends are in very good agreement, demonstrating that the state parameter approach is equally applicable to crushable, carbonate sands if representative soil 
data and material properties are available. This observation highlights the benefits of site-specific calibrations for both silica and carbonate sands on critical projects.

Data for dry M1 sand and saturated M3 sand are presented in $\psi_{0}$ form in Figs 17 and 18. Saturated M3 sand and M1 sand show the same behaviour in terms of $\psi_{0}$. This is

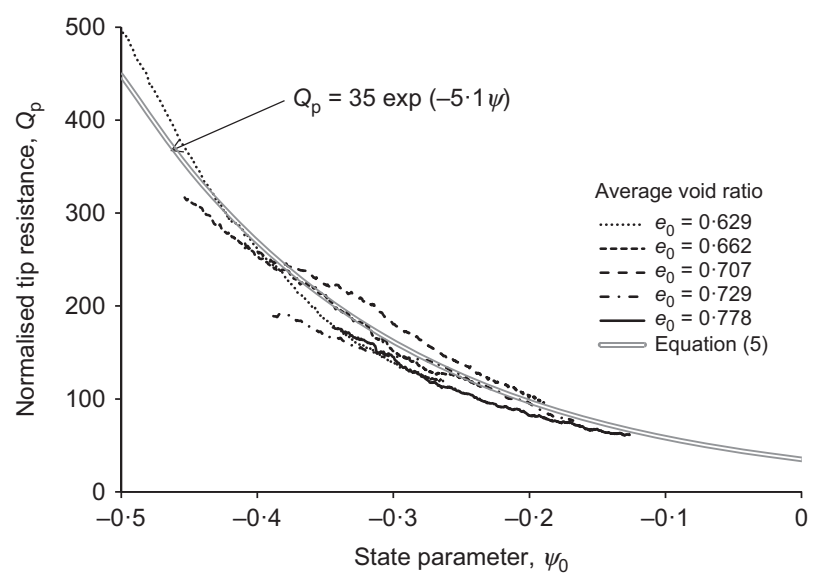

Fig. 16. State parameter interpretation of centrifuge tests on saturated M1 sand

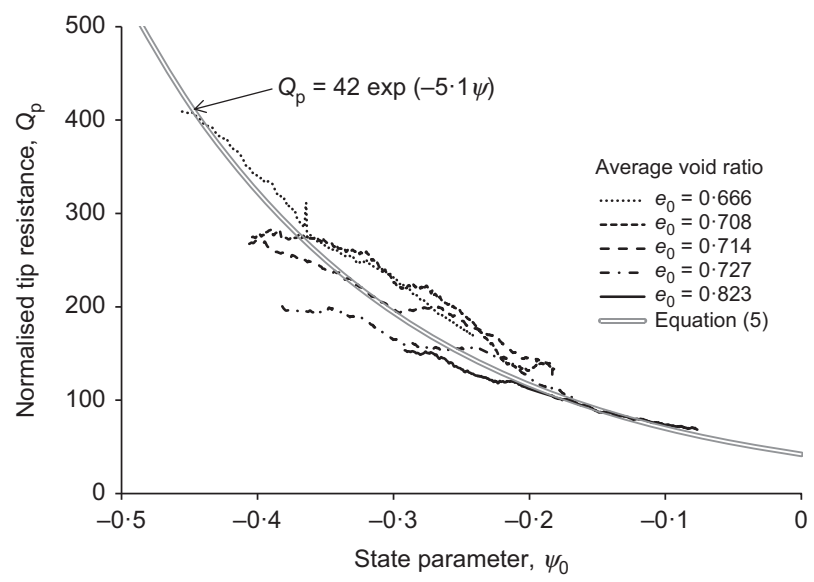

Fig. 17. State parameter interpretation of centrifuge tests on dry M1 sand, which shows higher tip resistance than for saturated sand in Fig. 11

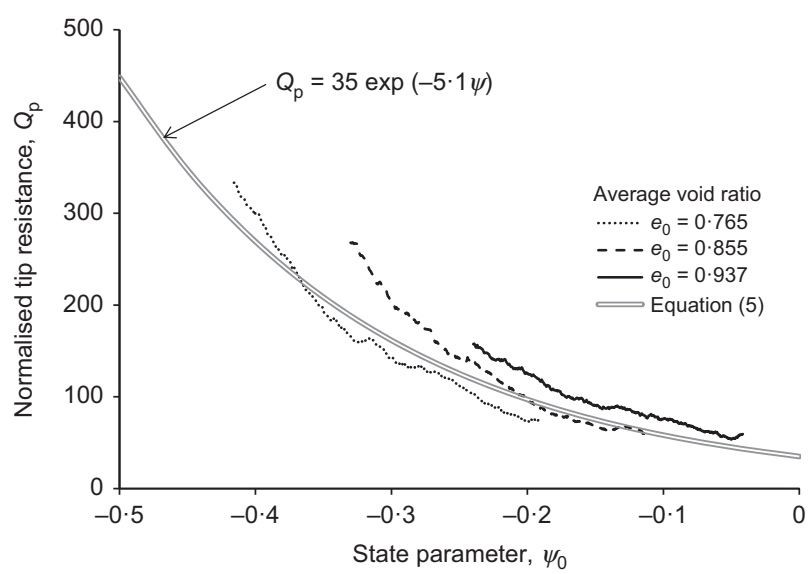

Fig. 18. State parameter interpretation of centrifuge tests on saturated M3 sand, showing similarity to M1 sand in Fig. 11 not the case if the two sands are compared in terms of void ratio (Table 5), since the CSL for M3 sand is different by 0.06 in terms of void ratio from that for M1. Dry M1 sand, however, shows a higher normalised tip resistance than saturated M1 sand at the same value of $\psi_{0}: k=42, m=5 \cdot 1$ compared to $k=35, m=5 \cdot 1$. This represents an approximately $17 \%$ increase in tip resistance when M1 sand is dry. The fact that the $m$ values are both $5 \cdot 1$ is interesting $-m$ is the scaling factor with $\psi_{0}$, whereas $k$ is simply the $Q_{\mathrm{p}}$ value when $\psi_{0}=0$.

\section{DISCUSSION}

Biogenic carbonate sands such as those addressed in this paper are generally composed of elongated particles with angular shape and intra-particle voids. When compressed or sheared, the particles exhibit crushing, from micro-crushing of the asperities to the breakage of the grains. The high void ratio and crushability of particles causes high compressibility. CPTs of carbonate sands tested in the calibration chamber and in the centrifuge demonstrate that, at comparable values of void ratio and stress level, the tip resistance is lower than in silica sands because the cone penetration causes a greater particle breakage around the tip of the probe in carbonate sands.

Many investigators have introduced empirical correction factors, such as the SCF (e.g. Lunne, 2006), in order to adjust the CPT data to 'equivalent' silica sand values and use various correlations relating $q_{\mathrm{t}}$ to engineering parameters established for silica sands. The SCF is applied to the cone resistance before estimating parameters such as relative density, angle of shear resistance, compressibility and lowstrain stiffness. The SCF is not a unique number, but a function strongly related to the type of sand involved, to its relative density and stress level within the CPT sounding. In light of these considerations the SCF must be used judiciously for broad application. For major earthwork and reclamation projects, the development of site-specific CPT-based correlations is recommended, as supported by the data presented in this paper. In the case of large projects involving unique soils for which limited geomechanical data are available in the technical literature, this may require a testing programme that is similar in scope to that described. The goal of the calibration test programme is the development of material-specific calibrations, as opposed to the application of an artificial correction factor.

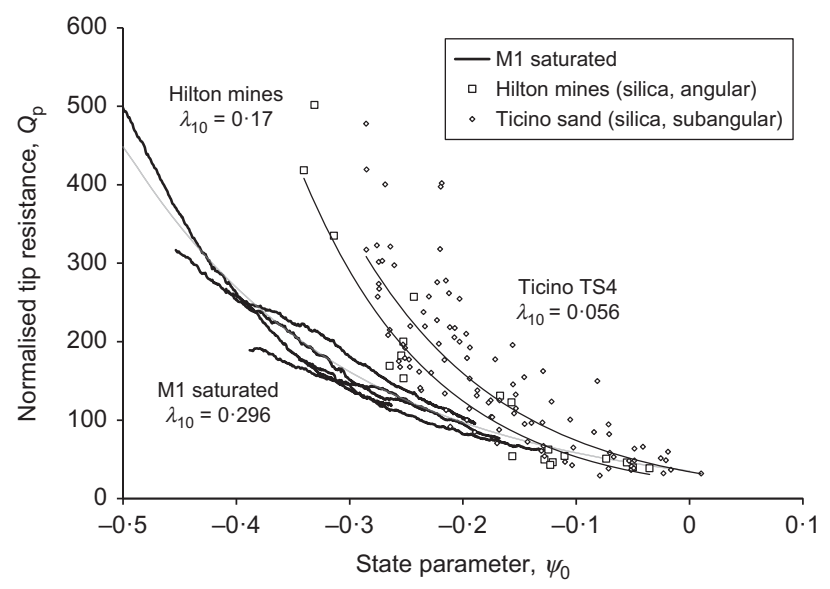

Fig. 19. Comparison of saturated M1 carbonate sand with siliceous sands of medium compressibility (Ticino sand) and high compressibility (Hilton mines sand) 


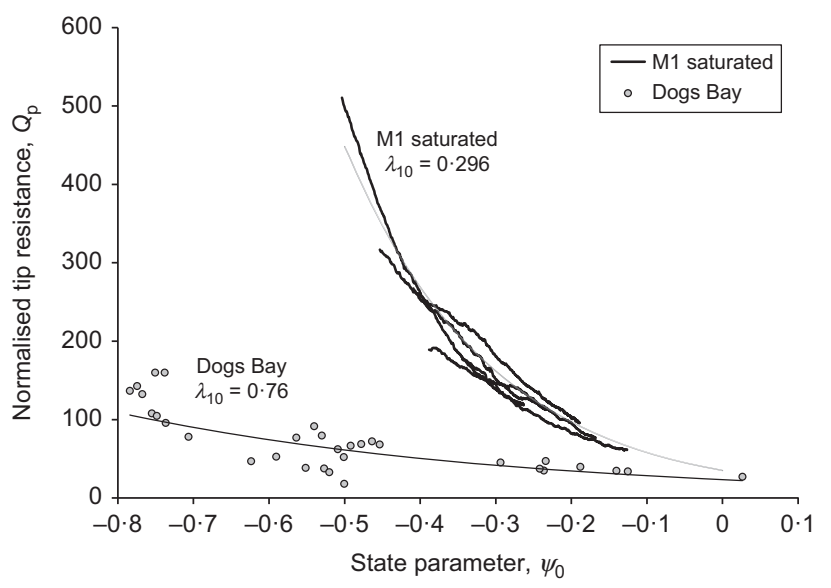

Fig. 20. Cone-pressuremeter calibration for Dogs Bay carbonate sand (Nutt, 1993) with CPT centrifuge calibration of M1 carbonate sand

The state parameter approach supported by critical state soil mechanics, cavity expansion theory and NorSand has provided a good Class B prediction of the CPT calibration for saturated M1 sand. In order to demonstrate the influence of carbonate sand behaviour on the CPT correlations, the M1 carbonate sand calibration is directly compared to several silica sands. Fig. 19 shows two silica sand calibrations (both large calibration chamber calibrations) for this comparison. The first is Ticino sand (Baldi et al., 1986), which is a reference sand commonly used for CPT correlations. The second is Hilton mine tailings (Harman, 1976), selected because it is an angular sand and has a higher compressibility than most silica sands. Compressibility in terms of CSL slope $\left(\lambda_{10}=0.296\right.$ for M1, 0.17 for Hilton mines and 0.056 for Ticino) is indicated in Fig. 19 for comparison. At a given value of $\psi_{0}$ the normalised tip resistance decreases with increasing compressibility. When thinking in terms of field measurements, for a given normalised tip resistance, the more compressible sand is in a denser state (i.e. lower value of $\psi_{0}$ ).

For the sake of comparison, a reference carbonate sand is Dogs Bay sand for which CSL data (Coop, 1990), index data (Golightly, 1988) and calibration test data for a conepressuremeter (Nutt, 1993) have been reported. To compare data, the authors have assumed that the tip resistance part of a cone-pressuremeter test is the same as for a standard CPT, and that all three sources have used the same Dogs Bay sand. Dogs Bay sand has a significantly higher compressibility $\left(\lambda_{10}=0.77\right)$ than M1 sand, and this is reflected in a much lower normalised tip resistance for a given state parameter, Fig. 20. The difference between M1 and Dogs Bay sands highlight that the natural variability of carbonate sands may require deposit-specific characterisation for large projects.

The behaviour of both carbonate sands confirms the trend of decreasing tip resistance with compressibility. Fig. 21 compares the $k$ and $m$ values with those for silica sands in Jefferies \& Been (2015). With the addition of six more sands to the original six sands in Been et al. (1987), the scatter around the fitted lines for $k$ and $m$ in terms of $\lambda_{10}$ increased. Adding M1 and Dogs Bay carbonate sands provides data well beyond the bounds of the original work, and a revision of the fits for $k$ and $m$ would be needed to extend the correlations to carbonate sands.

An unresolved issue arising from the centrifuge calibrations presented in this paper is the influence of saturation on the penetration resistance and behaviour of the M1 sand. Comparing Figs 12 (dry) and 11 (saturated), there are two features of note. First is that the overall gradient of the $q_{\mathrm{t}}$ plotted against $\sigma_{\mathrm{v}}^{\prime}$ curve is greater for the dry sand. Second,

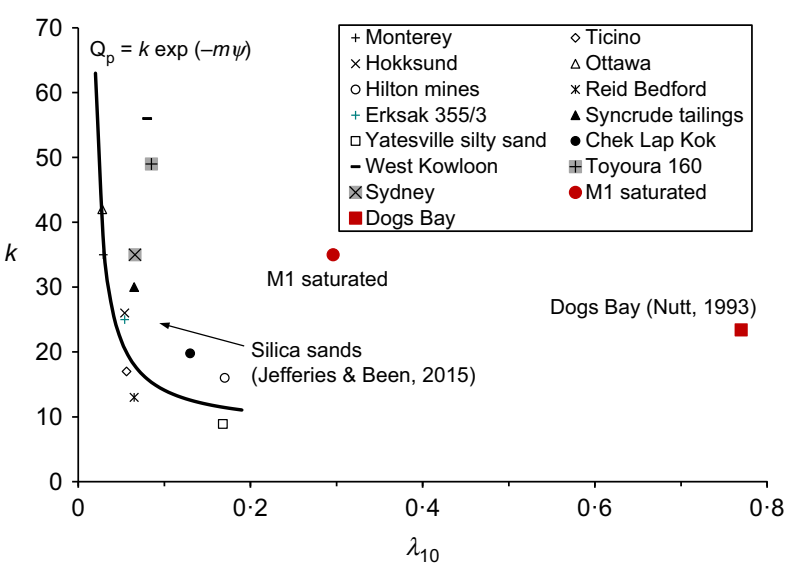

(a)

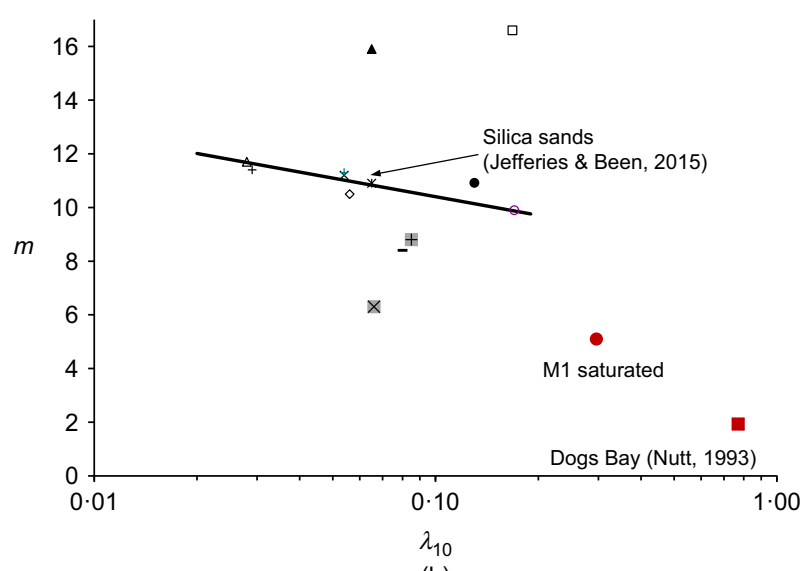

(b)

Fig. 21. State parameter interpretation coefficients (a) $k$ and (b) $m$ for silica sands (Jefferies \& Been, 2015) and for Dogs Bay and M1 sands. The latter (carbonate sands) lie well outside the range for silica sands on which the method was developed

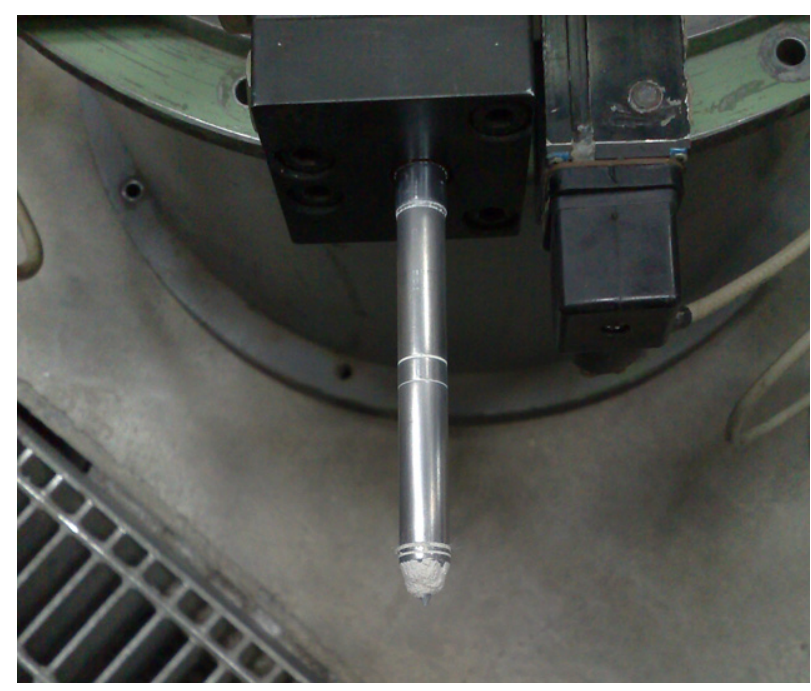

Fig. 22. Clumping of sand in front of the cone tip, after careful excavation following a centrifuge test

there are stress intervals where the $q_{\mathrm{t}}$ value either stays constant or even drops - for example, $e_{0}=0.708$ between vertical effective stresses of 180 and $220 \mathrm{kPa}$. In one instance, the miniature cone was retrieved from the test by carefully removing the sand around it. A clump of crushed sand/shells was observed to be sticking to the cone, as shown in Fig. 22. 
The authors speculate that when the dry sand is crushed by the penetration, the crushed shells may form a clump in front of the cone that grows with penetration, but that can grow too big to remain stable and then break away. This would explain the increased gradient (as the clump grows) and the constant or falling tip resistance (as the clump breaks up). An analogy might be the dead wedge that develops in passive pressure problems with large displacements (Hettiaratchi \& Reece, 1975; Been et al., 2008). Of course, this has implications for interpretation of the CPT in carbonate sand and, for the project in question, a different equation was used above and below the groundwater level in the fill. This issue is complicated by the fact that it could be scale-dependent, the scale of interest being the cone diameter in relation to the particle size of the sand. Whether the original particle size matters, or only the crushed particle size, is even less clear. Mineralogy of the particles may also influence the CPT data.

\section{CONCLUSIONS}

The work presented in this paper has illustrated important differences in the interpretation of CPT data in crushable, carbonate sand and silica-rich sand. The investigation has highlighted that empirical methods for estimating engineering properties using CPT data developed for silica sands should not be directly applied to carbonate sands. In the context of performance-based design, empirical, or screeninglevel, approaches to characterising unique soils such as crushable carbonate sands are insufficient, and soil-specific relationships based on engineering mechanics should be developed. For the engineering applications of primary interest in this investigation, the critical state soil mechanics approach was a very good starting point, and the approach contributed very well to project goals.

This work has demonstrated the utility of an integrated laboratory investigation that included centrifuge and calibration chamber tests, as well as more typical advanced laboratory testing such as triaxial and bender element tests. The work culminated in a soil-specific CPT calibration for a unique carbonate sand fill.

The project developed a geomechanically sound and robust correlation between the CPT and state parameter, from which other engineering parameters can be reliably estimated and applied to analysis of the sand fill behaviour at its in situ state. At the same time the limitation of an SCF and other ad hoc adjustments to CPT data in carbonate sands has been demonstrated. It is on this basis that the current authors highly recommend the development of soil-specific CPT correlations in unique soils and that empirical adjustment factors should be avoided, or judiciously used with great caution.

Further research is needed to develop the approach for wider application to compressible (carbonate) sands and silts.

\footnotetext{
NOTATIONS

$B$ Skempton pore pressure parameter

$C_{\mathrm{c}}$ compression index

$D$ dilation rate

$D_{50}$ mean grain size diameter

$d_{\mathrm{c}}$ cone diameter

$d_{\mathrm{c}}^{\prime} \quad$ effective cone diameter

$e$ void ratio

$e_{0}$ end of consolidation void ratio

$e_{\max }$ maximum void ratio

$e_{\min }$ minimum void ratio

$F$ calibration coefficient

$G_{\max } \quad$ small-strain shear stiffness

$G_{\mathrm{s}} \quad$ specific gravity

g Earth's gravitational acceleration
}

$H$ plastic hardening

$K_{0} \quad$ stress ratio at rest

$k$ fitting parameter

$M$ stress ratio at critical state

$M_{\text {tc }} \quad$ stress ratio at critical state in triaxial compression

$m$ fitting parameter

$N$ stress dilatancy volumetric coupling parameter (referring to Nova's flow rule)

$p_{\text {ref }}$ reference pressure

$p^{\prime}$ mean effective stress

$Q_{\mathrm{p}} \quad$ normalised cone resistance

$q$ stress deviator

$q_{\mathrm{t}}$ cone penetration test cone resistance

$S_{1} \quad$ fitting parameter

$s_{\mathrm{d}} \quad$ fitting parameter

$s_{\mathrm{h}} \quad$ fitting parameter

$s_{\mathrm{V}} \quad$ fitting parameter

$V_{\mathrm{s}}$ shear wave velocity

$\alpha$ calibration coefficient

$\beta$ calibration coefficient

$\Gamma_{1} \quad$ void ratio on the critical state line at $p^{\prime}=1 \mathrm{kPa}$

$\gamma_{\text {dry }}$ dry unit weight

$\gamma_{\max }$ maximum unit weight

$\gamma_{\min }$ minimum unit weight

$\gamma_{\text {tot }}$ saturated unit weight

$\gamma_{w}$ unit weight of water

$\varepsilon_{\mathrm{a}}$ axial strain

$\varepsilon_{\mathrm{q}} \quad$ deviatoric strain

$\varepsilon_{\mathrm{v}} \quad$ volumetric strain

$\eta$ stress ratio

$\lambda_{10}$ slope of the critical state line using logarithms to base 10

$v$ Poisson ratio

$\rho$ soil density

$\sigma_{\mathrm{h}}^{\prime} \quad$ horizontal effective stress

$\sigma_{\mathrm{v}}^{\prime} \quad$ vertical effective stress

$\phi_{\mathrm{cs}}^{\prime} \quad$ shearing resistance angle at critical state

$\psi \quad$ state parameter

$\psi_{0}$ initial state parameter

\section{REFERENCES}

Airoldi, S., Fioravante, V. \& Giretti, D. (2016). The ISMGEO seismic geotechnical centrifuge. Proceedings of the 3rd European conference on physical modelling in geotechnics (Eurofuge 2016), Nantes, France, pp. 185-190.

Almeida, M. S. S., Jamiolkowski, M. \& Peterson, R. W. (1991). Preliminary results of CPT tests in calcareous Quiou Sand. In Proceedings of the 1st international symposium on calibration chamber testing (ed. A. B. Huang), pp. 41-53. New York, NY, USA: Elsevier.

ASTM (2016a) D4254-16: Standard test methods for minimum index density and unit weight of soils and calculation of relative density. West Conshohocken, PA, USA: ASTM International.

ASTM (2016b) D4253-16: Standard test methods for maximum index density and unit weight of soils using a vibratory table. West Conshohocken, PA, USA: ASTM International.

Baldi, G., Bellotti, R., Ghionna, V., Jamiolkowski, M. \& Pasqualini, E. (1982). Design parameters for sand from CPT. Proceedings of the 2 nd European symposium on penetration testing, ESOPT 2 (ed. A. Verruijt), vol. 2, pp. 425-438. Rotterdam, the Netherlands: Balkema.

Baldi, G., Bellotti, R., Ghionna, N., Jamiolkowski, M. \& Pasqualini, E. (1986). Interpretation of CPT's and CPTU's, 2nd part. Proceedings of the 4th international geotechnical seminar, Nanyang, Singapore, pp. 143-156.

Baldi, G., Belloni, G. \& Maggioni, W. (1988). The ISMES geotechnical centrifuge. In Centrifuge 88 (ed. J. F. Corté), pp. 45-48. Rotterdam, the Netherlands: Balkema.

Been, K. \& Jefferies, M. G. (1985). A state parameter for sands. Géotechnique 35, No. 2, 99-112, http://dx.doi.org/10.1680/geot. 1985.35.2.99.

Been, K., Crooks, J. H. A., Becker, D. E. \& Jefferies, M. G. (1986). The cone penetration test in sands: Part I, state parameter interpretation. Géotechnique 36, No. 2, 239-249, http://dx.doi. org/10.1680/geot.1986.36.2.239. 
Been, K., Jefferies, M. G., Crooks, J. H. A. \& Rothenberg, L. (1987). The cone penetration test in sands: Part II, general inference of state. Géotechnique 37, No. 3, 285-299, http://dx.doi.org/ 10.1680/geot.1987.37.3.285.

Been, K., Sancio, R. B., Ahrabian, D., van Kesteren, W., Croasdale, K. R. \& Palmer, A. C. (2008). Subscour displacement in clays from physical model tests. In Proceedings of the international pipeline conference, IPC 64186. New York, NY, USA: American Society of Mechanical Engineers (ASME).

Bellotti, R. \& Jamiolkowski, M. (1991). Evaluation of CPT and $D M T$ in crushable and silty sands, 3rd Interim Report to ENEL C.R.I.S. Milan, Italy: National Electric Power Company.

Bellotti, R., Bizzi, G. \& Ghionna, V. (1982). Design, construction and use of a calibration chamber. In Proceedings of the 2nd European symposium on penetration testing, ESOPT 2 (ed. A. Verruijt), vol. 2, pp. 439-446. Rotterdam, the Netherlands: Balkema.

Bolton, M. D., Gui, M. W., Garnier, J., Corte, J. F., Bagge, G., Laue, J. \& Renzi, R. (1999). Centrifuge cone penetration tests in sand. Géotechnique 49, No. 4, 543-552, http://dx.doi.org/10.1680/ geot.1999.49.4.543.

Chapman, G. (1974). A calibration chamber for field test equipment. Proceedings of the 1st European symposium on penetration testing, Stockholm, Sweden, vol. 2, pp. 59-65.

Coop, M. R. (1990). The mechanics of uncemented carbonate sands. Géotechnique 40, No. 4, 607-626, http://dx.doi.org/10.1680/ geot.1990.40.4.607.

Coop, M. R. \& Airey, D. W. (2003). Carbonate sands. In Characterisation and engineering properties of natural soils (eds T. S. Tan, K. K. Phoon, D. W. Hight and S. Leroueil), vol. 2, pp. 1049-1086. Lisse, the Netherlands: Swets \& Zeitlinger.

Fioravante, V. \& Giretti, D. (2016). State parameter of sands from centrifuge cone penetration test. Proceedings of the 3rd European conference on physical modelling in geotechnics (Eurofuge 2016), Nantes, France, pp. 66-71.

Fioravante, V., Jamiolkowski, M., Ghionna, V. N. \& Pedroni, S. (1998). Stiffness of carbonate Quiou sand from CPT. In Geotechnical site characterisation (eds P. K. Robertson and P. W. Mayne), vol. 2, pp. 1039-1049. Rotterdam, the Netherlands: Balkema.

Fretti, C., Lo Presti, D. C. F. \& Pedroni, S. (1995). A pluvial deposition method to reconstitute well-graded sand specimens. Geotech. Testing J., GTJODJ 18, No. 2, 292-298.

Giretti, D., Fioravante, V., Been, K. \& Dickenson, S. (2017). Mechanical properties of a carbonate sand from a dredged hydraulic fill. Géotechnique, in press.

Golightly, C. R. (1988). Engineering properties of carbonate sands. $\mathrm{PhD}$ thesis, Department of Civil Engineering, University of Bradford, Bradford, UK.

Gui, M. W. \& Bolton, M. D. (1998). Geometry and scale effects in CPT and pile design. In Geotechnical site characterisation (eds P. K. Robertson and P. W. Mayne), vol. 2, pp. 1063-1068. Rotterdam, the Netherlands: Balkema.

Harman, D. E. (1976). A statistical study of static cone bearing capacity, vertical effective stress, and relative density of dry and saturated fine sands in a large triaxial testing chamber. MSc thesis, University of Florida, Gainesville, FL, USA.

Hettiaratchi, D. R. P. \& Reece, A. R. (1975). Boundary wedges in two-dimensional passive soil failure. Géotechnique 25, No. 2, 197-220, http://dx.doi.org/10.1680/geot.1975.25. 2.197 .
Jamiolkowski, M. B., Lo Presti, D. C. F. \& Manassero, M. (2003). Evaluation of relative density and shear strength from CPT and DMT. In Soil behavior and soft ground construction (eds J. T. Germaine, T. C. Sheahan and R. V. Whitman), Geotechnical Special Publication No. 119, pp. 201-238. Reston, VA, USA: American Society of Civil Engineers.

Jefferies, M. G. (1993). Nor-Sand: a simple critical state model for sand. Géotechnique 43, No. 1, 91-103, http://dx.doi.org/ 10.1680/geot.1993.43.1.91.

Jefferies, M. \& Been, K. (2006). Soil liquefaction; a critical state approach. London, UK and New York, NY, USA: Taylor and Francis.

Jefferies, M. \& Been, K. (2015). Soil liquefaction; a critical state approach, 2nd edn. London, UK and New York, NY, USA: CRC Press.

Klotz, E. U. \& Coop, M. R. (2001). An investigation of the effect of soil state on the capacity of driven piles in sands. Géotechnique 51, No. 9, 733-751, http://dx.doi.org/10.1680/geot.2001.51.9. 733.

Lambe, T. W. (1973). Predictions in soil engineering. Géotechnique 23, No. 2, 149-202, http://dx.doi.org/10.1680/geot.1973. 23.2.151.

Lunne, T. (2006). Guidelines for use and interpretation of CPT in hydraulically constructed fills, NGI Report 20041367-3. Oslo, Norway: NGI.

Lunne, T. \& Christoffersen, H. P. (1983). Interpretation of cone penetrometer data for offshore sands. Proceedings of the offshore technology conference, Houston, TX, USA, paper OTC 4464.

Mayne, P. W. (2006). In-situ test calibrations for evaluating soil parameters. In Characterization and engineering properties of natural soils (eds T. S. Tan, K. K. Phoon, D. W. Hight and S. Leroueil), vol. 3, pp 1-57. London, UK: Taylor and Francis.

Mayne, P. W. (2007). Cone penetration testing. A synthesis of highway practice, National Cooperative Highway Research Program (NCHRP) Synthesis 368. Washington, DC, USA: Transportation Research Board.

Nutt, N. R. F. (1993). Development of the cone-pressuremeter. $\mathrm{PhD}$ thesis, University of Oxford, Oxford, UK.

Parkin, A., Holden, J., Aamot, K., Last, N. \& Lunne, T. (1980). Laboratory investigations of CPTs in sand. NGI Report S2108-9. Oslo, Norway: NGI.

Robertson, P. K. \& Campanella, R. G. (1983). Interpretation of cone penetration tests. Part I: Sand. Can. Geotech. J. 20, No. 4, 718-733.

Schmertmann, J. H. (1978). Guidelines for cone penetration test, performance and design, Report FHWA-TS-787-209. Washington, DC, USA: Federal Highway Administration.

Shuttle, D. A. \& Jefferies, M. G. (1998). Dimensionless and unbiased CPT interpretation in sand. Int. J. Numer. Analyt. Methods Geomech. 22, No. 5, 351-391.

Sladen, J. A. (1989). Problems with interpretation of sand state from cone penetration test. Géotechnique 39, No. 2, 323-332, http://dx.doi.org/10.1680/geot.1989.39.2.323.

Van't Hoff, J. \& van der Kolff, A. N. (eds) (2012). Hydraulic fill manual for dredging and reclamation works. Leiden, the Netherlands: CRC Press/Balkema, Taylor and Francis Group.

Verdugo, R. \& Ishihara, K. (1996). The steady state of sandy soils. Soils Found. 36, No. 2, 81-91.

Vesic, A. S. (1965). Ultimate load and settlement of deep foundations in sand. In Proceedings of the symposium on bearing capacity and settlement of foundations in sand, pp. 53-68. Durham, NC, USA: Duke University. 